Issued by Sandia National Laboratories, operated for the United States Department of Energy by Sandia Corporation.

NOTICE: This report was prepared as an account of work sponsored by an agency of the United States Government. Neither the United States Government, nor any agency thereof, nor any of their employees, nor any of their contractors, subcontractors, or their employees, make any warranty, express or implied, or assume any legal liability or responsibility for the accuracy, completeness, or usefulness of any information, apparatus, product, or process disclosed, or represent that its use would not infringe privately owned rights. Reference herein to any specific commercial product, process, or service by trade name, trademark, manufacturer, or otherwise, does not necessarily constitute or imply its endorsement, recommendation, or favoring by the United States Government, any agency thereof, or any of their contractors or subcontractors. The views and opinions expressed herein do not necessarily state or reflect those of the United States Government, any agency thereof, or any of their contractors.

Printed in the United States of America. This report has been reproduced directly from the best available copy.

Available to DOE and DOE contractors from

Office of Scientific and Technical Information

P.O. Box 62

Oak Ridge, TN 37831

Prices available from (703) 605-6000

Web site: http://www.ntis.gov/ordering.htm

Available to the public from

National Technical Information Service

U.S. Department of Commerce

5285 Port Royal Rd

Springfield, VA 22161

NTIS price codes

Printed copy: A04

Microfiche copy: A01

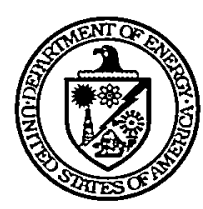




\section{DISCLAIMER}

Portions of this document may be illegible in electronic image products. Images are produced from the best available original document. 
SAND2000-8248

Unlimited Release

Printed June 2000

\title{
A Small Form Factor Solid-State Hydrogen Sensor Package
}

\author{
Scott E. Faas \\ Advanced Concepts and Applications Department \\ Sandia National Laboratories \\ P.O. Box 969 \\ Livermore, CA 94551-0969
}

George R. Dulleck

Integrated Microsystems Department

Sandia National Laboratories

P.O. Box 5800

Albuquerque, NM 87135-0619

\begin{abstract}
The Sandia Robust Hydrogen Sensor is a low power, integrated circuit based miniature hydrogen transducer. This report documents the design, testing, and calibration activities for integrating the Sandia Robust Hydrogen Sensor transducer and supporting electronics into a small form factor package.
\end{abstract}


This page left blank on purpose. 


\section{Table of Contents}

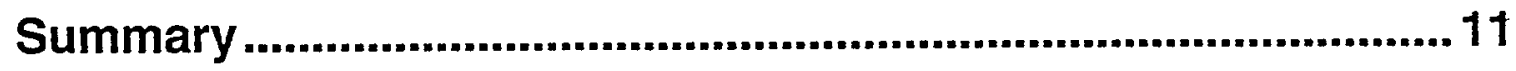

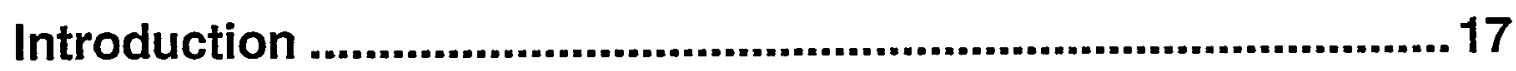

Theory of Hydrogen FET Operation ..............................................18

Electronic Design and Fabrication ................................................20

Sandia Robust Hydrogen Sensor ..........................................................20

Circuit Design ............................................................................................23

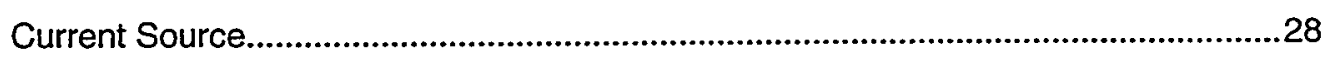

Gain Block and Level Adjustment...........................................................................30

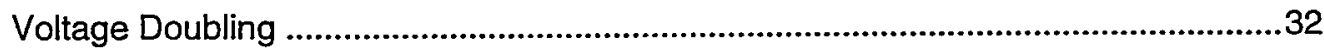

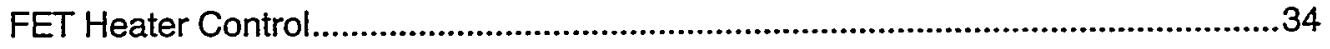

Board Layout and Interfaces....................................................................36

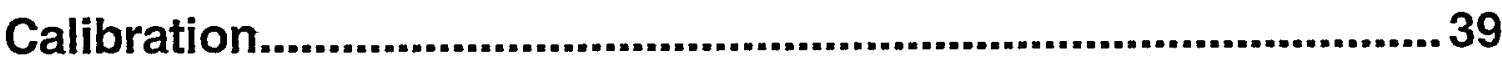

Calibration Data......................................................................................39

FET Response to a Hydrogen/Nitrogen Atmosphere.............................41

Effect of Oxygen on FET Response to Hydrogen ..................................42

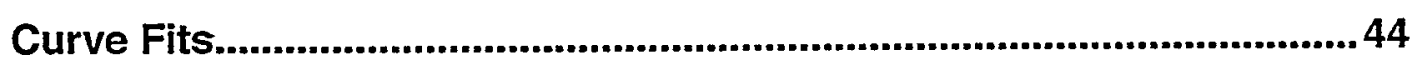

Performance .................................................................................. 48

Repeatability and Accuracy ....................................................................48

Variation Between Parts ..........................................................................55

Temperature Sensitivity.............................................................................52

Response Time.............................................................................................54

Conclusions and Recommendations .........................................56

References ................................................................................. 57 
APPENDIX A - Initial Specifications ...........................................59

Appendix B - Version 2 Hydrogen FET Bias Circuit....................65

Appendix C - Data Tabulations .....................................................67 


\section{Figures}

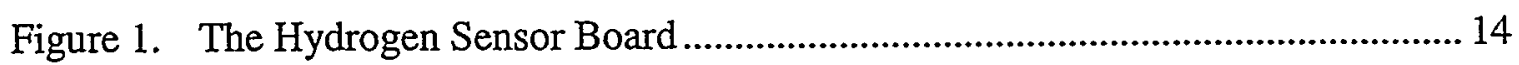

Figure 2. Polynomial Curve Fit of the Calibration Data ................................................. 15

Figure 3. The Hydrogen Sensor Board. ................................................................... 17

Figure 4. Construction and operation of a Hydrogen-Sensitive FET ............................. 18

Figure 5. Pictorial representation of hydrogen interacting with the palladium alloy/silicon nitride junction............................................................................... 19

Figure 6. Layout of the Sandia Robust Hydrogen Sensor. ............................................... 20

Figure 7. Closeup view of Sandia Robust Hydrogen Sensor............................................ 21

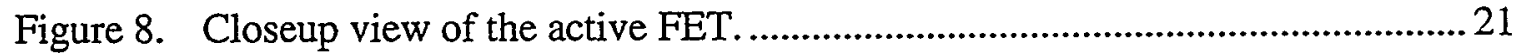

Figure 9. The Sandia Robust Hydrogen Sensor packaged as a 16 pin Dual Inline

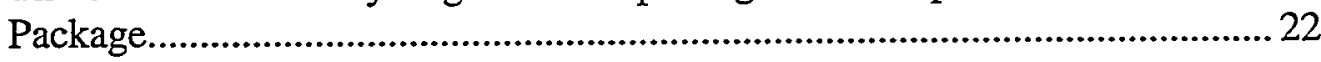

Figure 10. Pin Designations for the TA770 (16 pin DIP) Sandia Robust Hydrogen

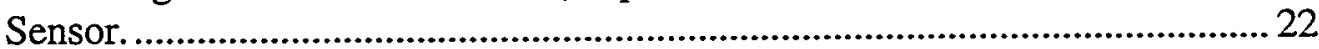

Figure 11. Electrical Schematic for the Hydrogen Sensor Board ..................................... 26

Figure 12. Constant Current Source Circuit................................................................ 28

Figure 13. Zero and Scale adjusting circuit.................................................................... 30

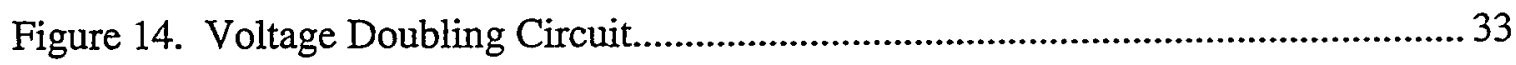

Figure 15. Heater Control Circuit. ............................................................................... 35

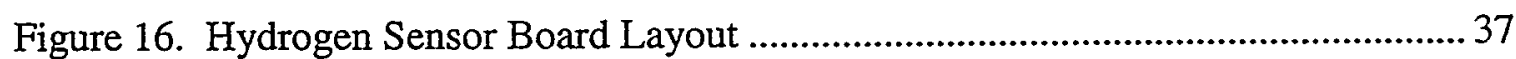

Figure 17. Connections for Powering the Hydrogen Sensor Board from an External Power Supply.

Figure 18. Connections for Powering the Hydrogen Sensor Board from the Battery Powered Telemetry System.................................................................................. 38

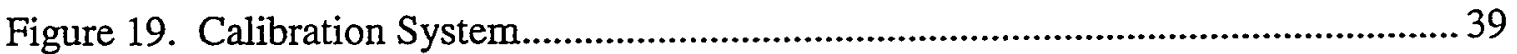

Figure 20. Typical Output Data for Hydrogen Sensor Board Calibration.......................... 41

Figure 21. Response of Hydrogen FET 2541 to varying hydrogen concentrations in a nitrogen atmosphere.

Figure 22. Response of Hydrogen FET 2541 to low hydrogen concentrations in a nitrogen/oxygen atmosphere

Figure 23. Response of Hydrogen FET 2541 for hydrogen in a nitrogen/oxygen atmosphere. 
Figure 24. Response of Hydrogen FET 2541 to hydrogen concentrations in a nitrogen/oxygen atmosphere replotted using a new concentration ratio .45

Figure 25. Figure 24 plotted with a logarithmic y axis.......................................................45

Figure 26. Comparison of a straight-line and $5^{\text {th }}$ order polynomial fit.............................. 46

Figure 27. Temperature Sensitivity Testing of the Hydrogen Sensor Boards ................... 52

Figure 28. Effect of Temperature on the Hydrogen Sensor Board Output. ...................... 53

Figure 29. Comparison of Hydrogen Sensor Response Rate Between Hot and Cold

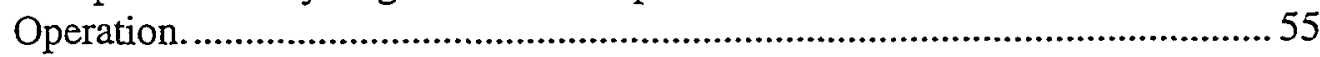

Figure A-1. Power FET Heater Power Control Sequence ……………............................. 60

Figure A-2. Hydrogen Sensor Add-On Board Interfaces................................................. 62

Figure A-3. Maximum Area Allocated for Add-On Board................................................ 63

Figure B-1. Version 2 Hydrogen FET Biasing Circuit Schematic..................................... 66 


\section{Tables}

Table 1. Design Constraints ..................................................................................... 13

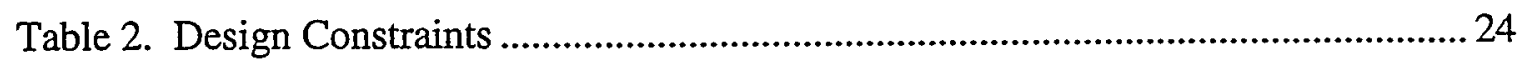

Table 3. Parts List for the Hydrogen Sensor Board ........................................................ 27

Table 3. Parts List for the Hydrogen Sensor Board - Continued ....................................... 28

Table 4. Effect of R24 Resistance on the Current Source Temperature Coefficient ....... 29

Table 5. Voltages through the gain block and level shifters .............................................. 32

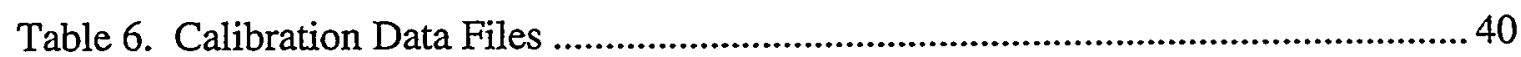

Table 7. Curve Fit Coefficients for FETs 2536 and 2541 ................................................4 47

Table 8. Comparison of unheated calibration results when the FETs were heated in

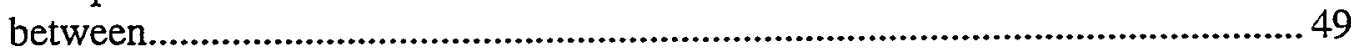

Table 9. Comparison of unheated calibration results when the FETs were not heated

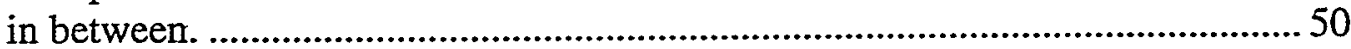

Table 10. FET Threshold Voltages ................................................................................. 51

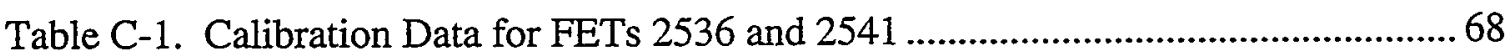


This page left blank on purpose. 


\section{Summary}

A hydrogen sensor was required by the Enhanced Surveillance Program (ESP) SN13 task: Embedded Instrumentation for Non-nuclear Components. Based on component gas sample data, a low power sensor capable of measuring hydrogen concentrations from 10 to 10,000 ppm was desired. The Sandia Robust Hydrogen Sensor met the sensitivity and power consumption requirements.

The Sandia Robust Hydrogen Sensor is only a transducer. Considerable supporting electronics are required to bias the hydrogen sensing Field Effect Transistor (FET) on the Sandia Robust Hydrogen Sensor, condition the sensor output, and controllably heat the hydrogen sensing FET to optimize response to changing conditions.

This report documents the design, testing, and calibration activities for producing an integrated transducer and supporting electronics package called the Hydrogen Sensor Board.

Power requirements were quite stringent. Current Integrated Nuclear Materials Management (INuMM) program telemetry packages were using sensors consuming 4 milliamps of current or less. A demonstration model of the INuMM Electronic Sensor Platform, an integrated telemetry/sensor package, had used a Sandia Robust Hydrogen Sensor [Mickelson, 1997]. This implementation of the Sandia Robust Hydrogen Sensor had successfully used only the Field Effect Transistor (FET) portion of the sensor, and, in order to reduce power consumption, had not powered the sensor's FET heaters.

The Hydrogen Sensor Board had several main functions, hydrogen FET power and signal conditioning, power FET (temperature control) power and conditioning and a timing circuit. The board was separated into two sections - hydrogen FET side and power FET side. Each board section required its own power and its own ground. Prior knowledge and circuitry were used whenever available.

The Hydrogen Sensor Board functions were as follows:

\section{Hydrogen FET side of the circuit board}

a. Receive power pulse from the telemetry/data acquisition system.

b. Generate acceptable voltage and current to power the hydrogen FET.

c. Scale the hydrogen FET output voltage to match the data acquisition system input requirement.

d. Provide power FET heater circuit turn on signal at trailing edge of the power pulse from the telemetry/data acquisition system. 


\section{Power FET side of the circuit board}

a. Condition Power from an external source.

b. After receiving a signal from the hydrogen FET side of the board, bring the Sandia Robust Hydrogen Sensor chip up to a prescribed temperature (typically $90^{\circ} \mathrm{C}$ ) for a specific length of time, and then return to room temperature (remove heater power).

Several circuit designs for using the Sandia Robust Hydrogen Sensor were available from past applications. Portions of these designs were used in this design. One circuit in particular is used extensively by Sandia's Microsensor R\&D Department for testing and calibrating the Sandia Robust Hydrogen Sensor (version TA770). This design incorporated circuitry to accommodate a wide variation in the hydrogen FET threshold voltages. The hydrogen $\mathrm{FET}$ threshold voltage varies noticeably from chip to chip, and wafer to wafer.

The InuMM Electronic Sensor Platform used a circuit designed to use a few milliamps of current as opposed to the Microsensor R\&D Department system where current was not a concern. The battery-powered circuit did not include any temperature control circuits because it was an ultra low power system incapable of providing the current levels required by the power FETs. Because, power and circuit area available was limited, this circuit used a voltage doubling circuit to double the $3.6 \mathrm{~V}$ battery voltage insuring that the hydrogen FET could always be operated at its threshold voltage.

Circuit elements were used from both designs in addition to new elements required by the present application. Several major constraints had impact on the design elements and are listed in Table 1.

Because this circuit required the use of the on-chip heaters the circuit was split into two sections - one for the hydrogen FET side and one for the temperature control side. The hydrogen FET side used the telemetry/data acquisition system battery power while the Power FET side used an external power supply. This posed a potential problem since all the circuitry on the $\mathrm{H} 2$ sensor chip shared a common substrate making the substrate a common potential.

The sensor chip also had protection circuits that tied the drain of the hydrogen FET to the drain of one of the power FETs in order to provide ESD protection. The use of a protection circuit diode meant that the FETs drains must be biased properly with respect to each other in order to prevent the diode from being turned on. 


\section{Table 1. Design Constraints}

\section{Constraint}

- Low power draw - $<2.5 \mathrm{~mA}-$ less if possible

- Only 3.6 volts available.

- Single sided power supply

- Temperature control required as an option

- Temperature circuit must turn on (for controlled time) after data acquisition system reads hydrogen FET

Design impact

\section{Previous Design inputs}

Part of the circuit had to use low power parts

Need to generate higher voltage

OpAmps must be biased off ground and must operate rail-torail.

Need external power supply for temperature side of circuit

Not compatible with need to have low power draw.

A timer must be present in circuit
Single shot doubler circuit was used

Similar to previous design but with max current and timer control added

One impact of this requirement is that using the hydrogen FET by itself is fine, but using two different power supplies is only good if you don't turn on the protection diode. In this design, voltage is doubled by using a series capacitor technique. This provides very limited current capability. If the protection diode turns on and current is lost to the power side of the circuit, the hydrogen FET is not properly biased and a hydrogen measurement cannot be made.

This means that the hydrogen FET side and the temperature control side must be completely isolated from each other (power and ground). Alternatively, the external power supply (on the power side) must be on at all times to prevent the protection diode from being turned on by the hydrogen FET side of the circuit. It was found through testing that it was impossible to isolate the hydrogen FET and power FET grounds forcing power to be applied to the power terminals at all times even if the power FETs are not operated.

The resulting electronic assembly is shown in Figure 1 and is called the Hydrogen Sensor Board. 


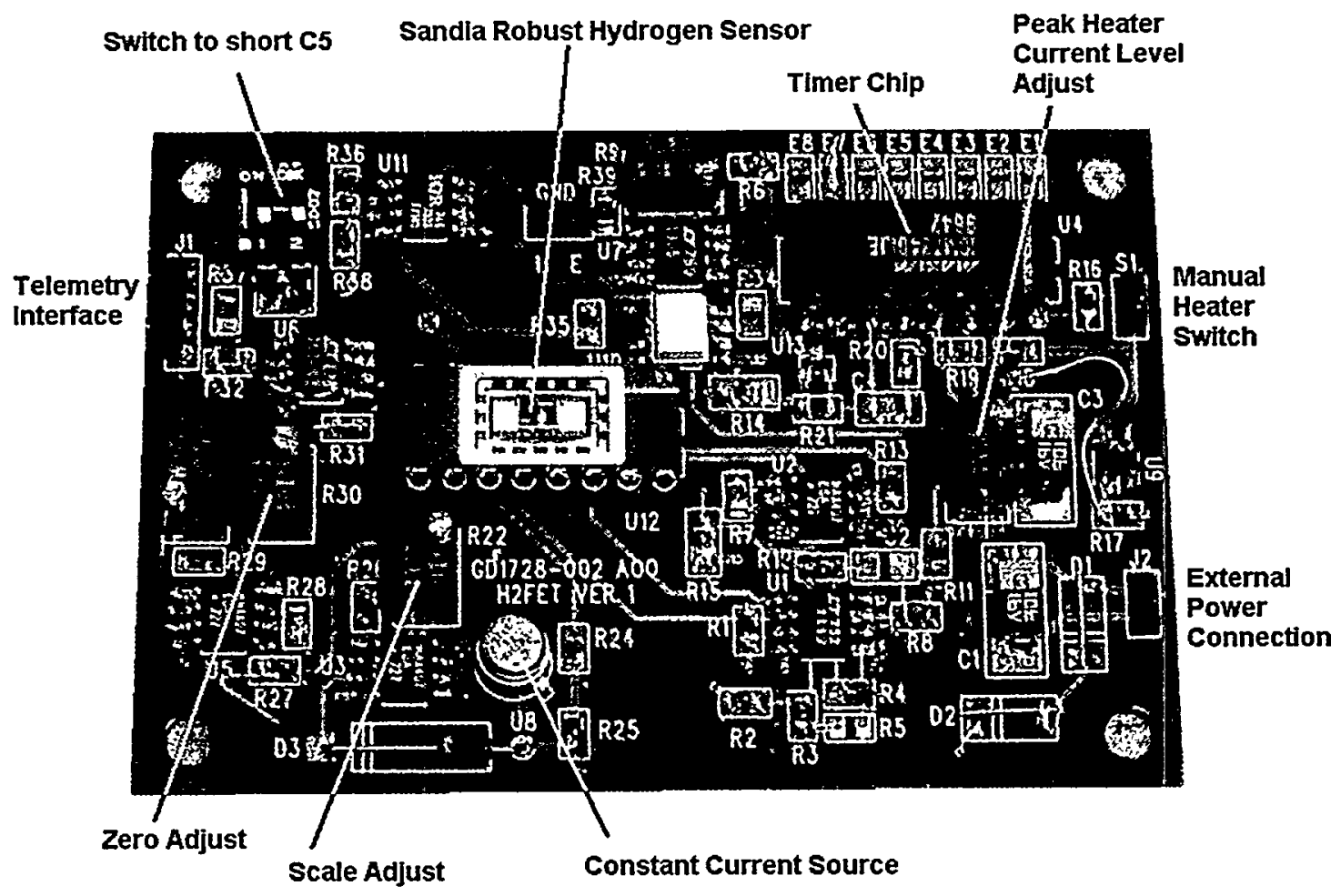

Figure 1. The Hydrogen Sensor Board

Two Hydrogen Sensor Boards were constructed and underwent calibration testing from October 1 through November 23, 1998. It was found that hydrogen FETs exposed to varying concentrations of hydrogen and oxygen could have their output voltages described by a single function of the form:

$$
\ln \left(\frac{\mathrm{C}_{\mathrm{H} 2}}{\mathrm{C}_{\mathrm{O} 2}^{1 / 3}}\right)=\mathrm{f}\left(\mathrm{V}_{\text {out }}\right)
$$

Figure 2 shows the data and curve fit for hydrogen concentrations ranging from $10 \mathrm{ppm}$ to $10,000 \mathrm{ppm}$ and oxygen concentrations from $3 \%$ to $20 \%$. 


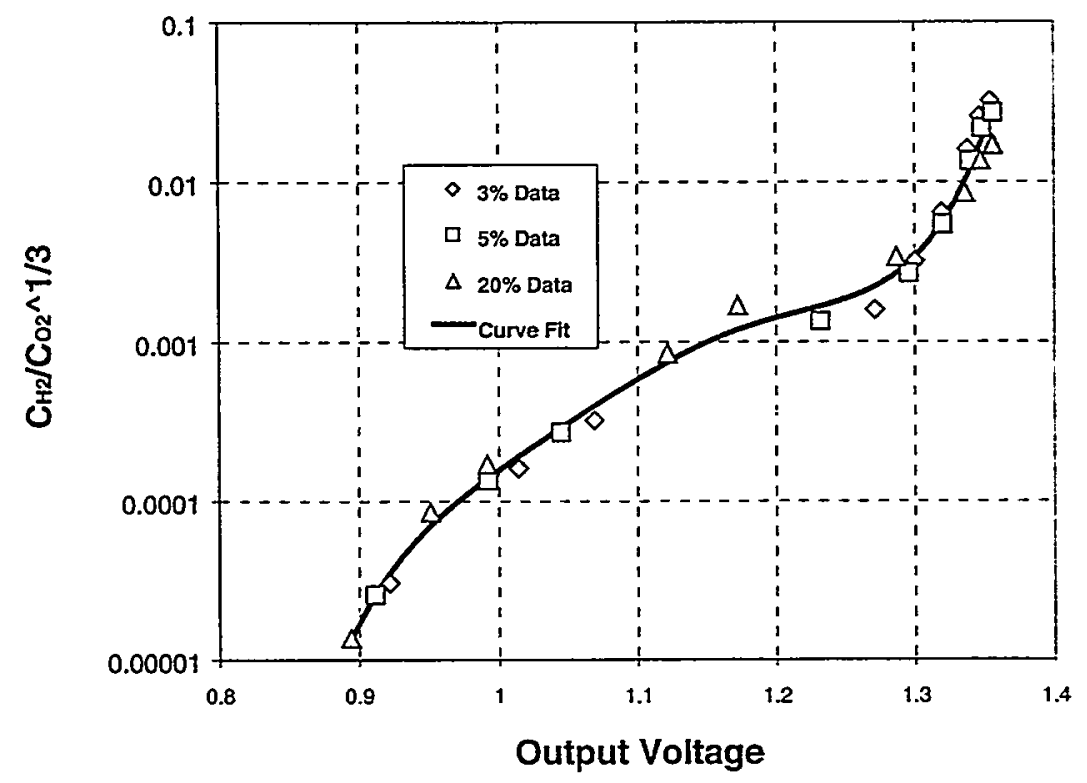

Figure 2. Polynomial Curve Fit of the Calibration Data

The calibration testing also provided data on how the hydrogen FET works as a sensor device. Some observations are:

1. Some hydrogen FETs show marked shifts in their performance after they have been heated and then cooled. It is recommended that the hydrogen FETs be operated unheated.

2. The speed of response of the hydrogen FETs tested to a step change in hydrogen level is not significantly different between heated and unheated operation when the sensors are in an enclosure with free volume. It is recommended that the hydrogen FETs be operated unheated to reduce power consumption.

3. The hydrogen FETs tested had the same threshold voltage change over a 10 ppm to $10,000 \mathrm{ppm}$ hydrogen concentration range. However, the absolute voltage ranges were quite different. Until hydrogen FETs become much more uniform in their response, each hydrogen FET will have to be calibrated prior to service. A standard calibration curve is not possible.

4. The hydrogen FET output, along with the signal conditioning, is noticeably sensitive to temperature. The hydrogen FET and its signal conditioning must be characterized for temperature response so this may be eliminated during data processing. 
This page left blank on purpose. 


\section{Introduction}

A hydrogen sensor was required by the Enhanced Surveillance Program (ESP) SN13 task: Embedded Surveillance for Non-nuclear Components. Based on component gas sample data, a low power sensor capable of measuring hydrogen concentrations from 10 to 10,000 ppm was desired. The Sandia Robust Hydrogen Sensor [Hughes et al, 1994] met the sensitivity and power consumption requirements.

The Sandia Robust Hydrogen Sensor is only a transducer. Considerable supporting electronics are required to bias the hydrogen sensing Field Effect Transistor (FET) on the Sandia Robust Hydrogen Sensor, condition the sensor output, and controllably heat the hydrogen sensing FET to optimize response to changing conditions. Initial specifications for the supporting electronics is shown in Appendix A.

This report documents the design, testing, and calibration activities for producing an integrated transducer and supporting electronics package: the Hydrogen Sensor Board shown in Figure 3.

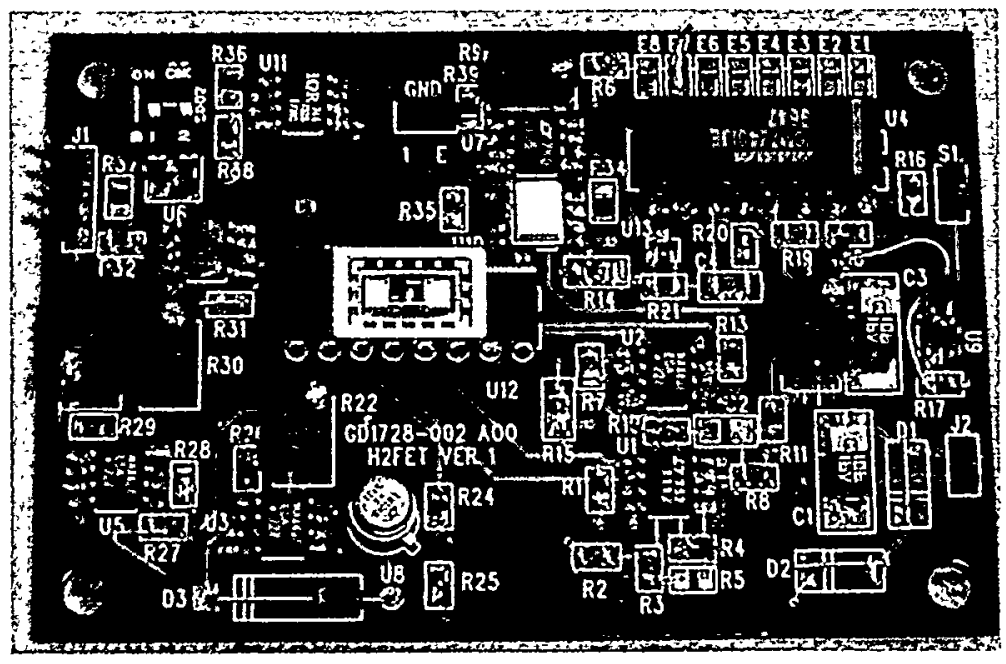

Figure 3. The Hydrogen Sensor Board. 


\section{Theory of Hydrogen FET Operation}

In this section, a condensation of Lundström's original paper will be presented to explain the operation of the hydrogen FET [Lundström, 1981].

Figure 4 shows the basic construction and method for operating a hydrogen FET.

Figure 5 shows how hydrogen is adsorbed onto and absorbed into the palladiumnickel layer producing hydrogen ions at the silicon nitride interface. The number of hydrogen atoms at the palladium alloy/silicon nitride interface affects the threshold voltage read out by the circuit in Figure 4 .

Specifically, the more atoms present at the palladium alloy/silicon nitride interface, the lower the threshold voltage. The theoretical steady-state drop in threshold voltage due to the presence of hydrogen is related to the concentration of hydrogen in the inert atmosphere above the FET, in terms of gas partial pressure, by the following equation:

$$
\frac{1}{\Delta V}=K_{1} \sqrt{\frac{1}{p_{\mathrm{H}_{2}}}}
$$

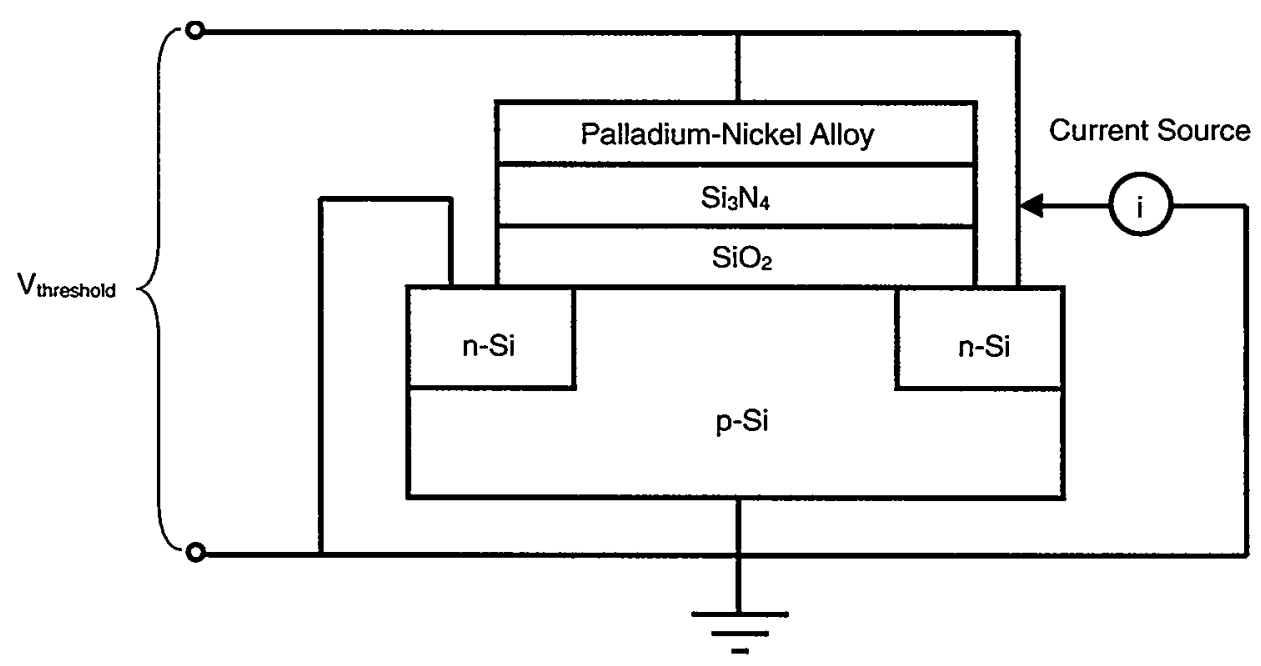

Figure 4. Construction and operation of a Hydrogen-Sensitive FET 


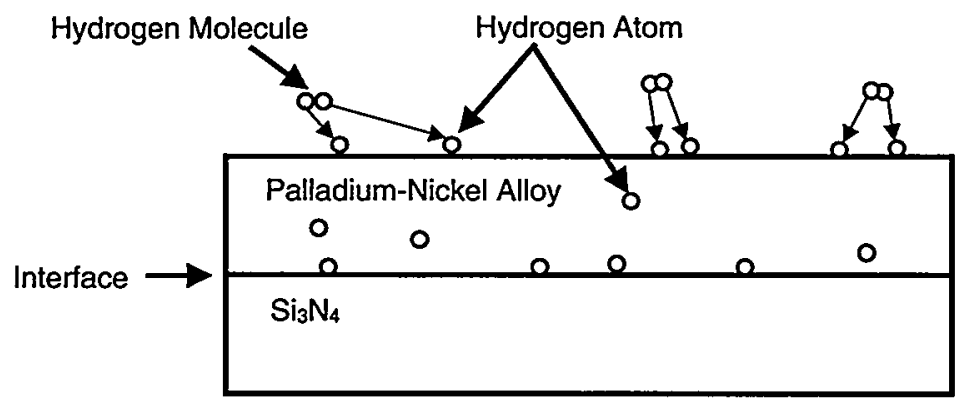

Figure 5. Pictorial representation of hydrogen interacting with the palladium alloy/silicon nitride junction.

When oxygen is present, the hydrogen and oxygen atoms interact at the surface of the palladium alloy producing water and reducing the number of hydrogen atoms present at the palladium alloy/silicon nitride interface, thereby reducing the threshold voltage drop. The equation for the theoretical steady-state drop in threshold voltage becomes:

$$
\frac{1}{\Delta V}=K_{2} \sqrt{\frac{\mathrm{p}_{\mathrm{o}_{2}}}{\mathrm{p}_{\mathrm{H}_{2}}}}
$$

where now the partial pressure of oxygen plays a role in defining the drop in threshold voltage.

In his paper, Lundström notes that theory does not fully represent all of the complexities of reality. In the chapter discussing the calibration data, we will see how well theory matches observed behavior. 


\section{Electronic Design and Fabrication}

\section{Sandia Robust Hydrogen Sensor}

The Sandia Robust Hydrogen Sensor is wide range hydrogen sensor using a Field Effect Transistor (FET) with a catalytic metal gate for measuring hydrogen concentrations below $10,000 \mathrm{ppm}$ and a catalytic metal chemiresistor for measuring hydrogen concentrations above $10,000 \mathrm{ppm}$ to $95 \%$.

The hydrogen FET chip was available in several versions. One version (typically used in development) contained a number of hydrogen FETs, A hydrogen sensing chemiresistor, multiple bipolar junctions used for temperature monitors and several power FETs used for chip heating. An image of the chip is shown in Figure 6. Figures 7 and 8 show the active FET.

When packaged as a 16 DIP package, the Sandia Robust Hydrogen Sensor appears as shown in Figure 9. The wiring description for the 16 pin DIP package, called the TA770, is shown in Figure 10.

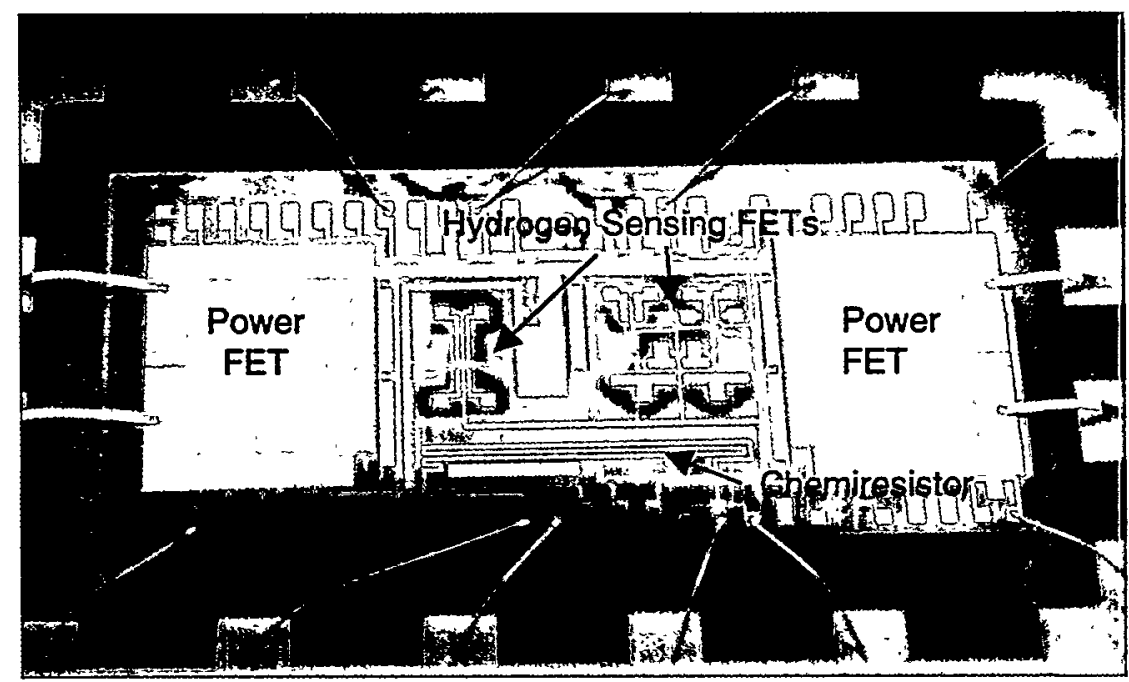

Figure 6. Layout of the Sandia Robust Hydrogen Sensor. 


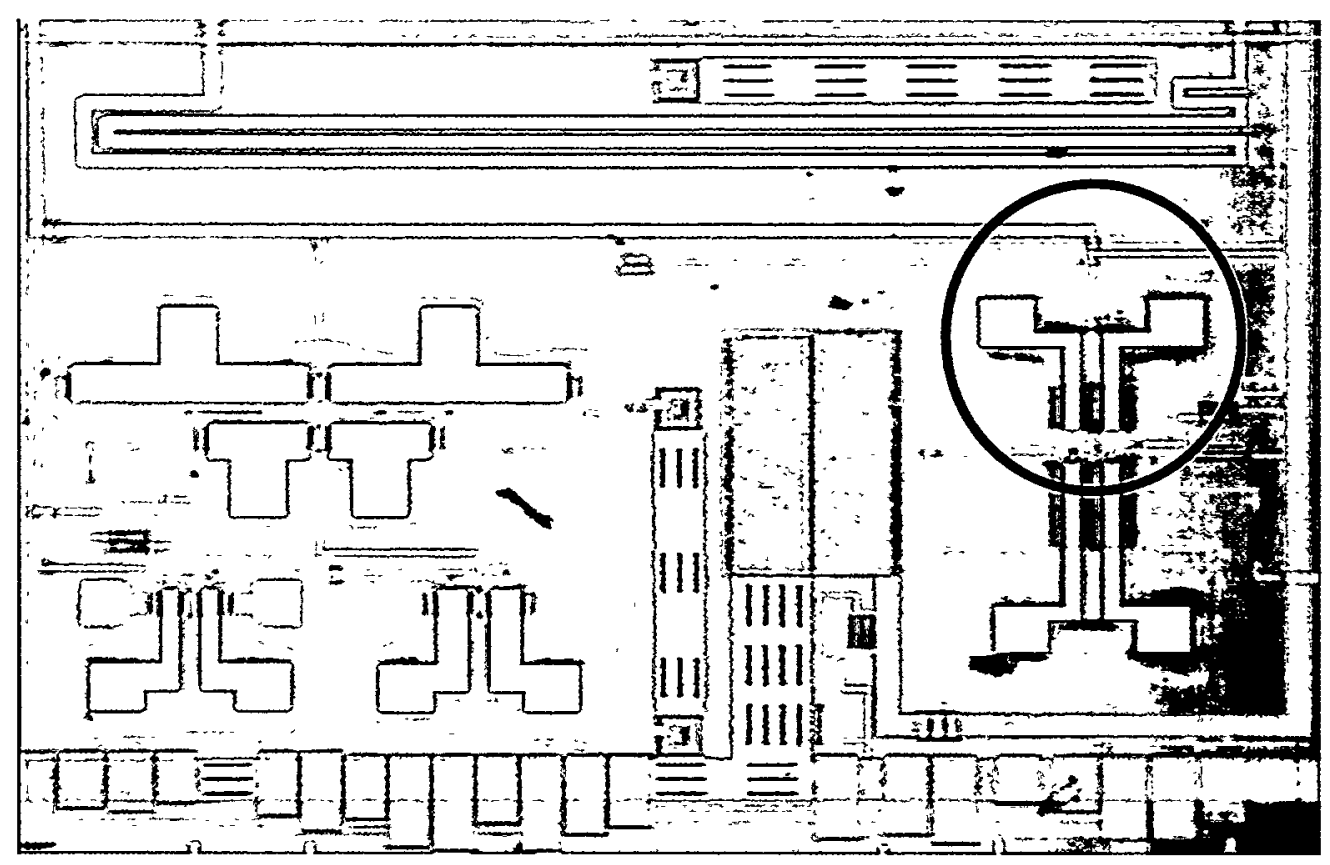

Figure 7. Closeup view of Sandia Robust Hydrogen Sensor. The serpentine trace at the top of the picture is the chemiresistor. The circled Field Effect Transistor is the active FET on this device. The other FETs visible are spares. The dark splotches are dust particles.

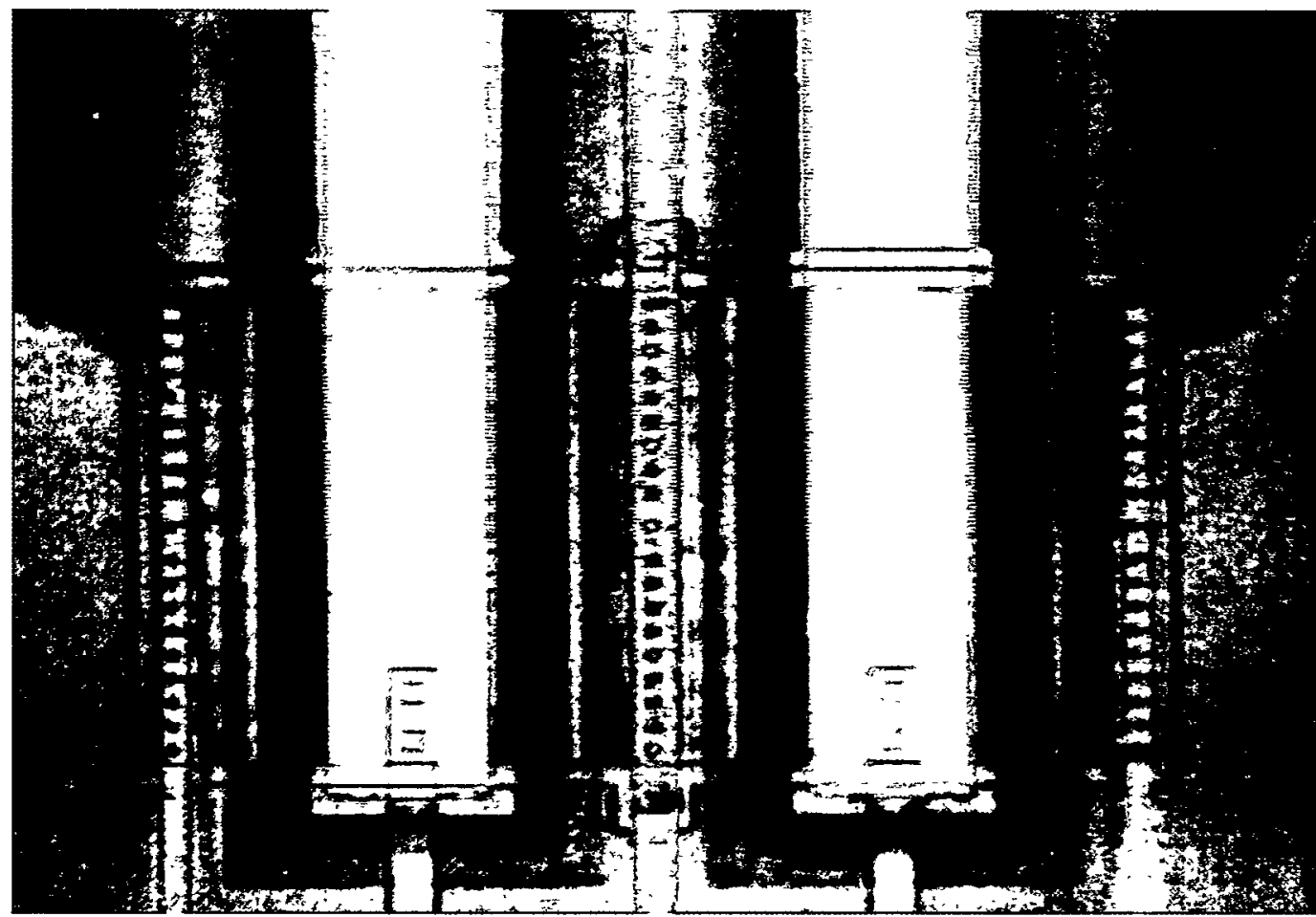

Figure 8. Closeup view of the active FET. 


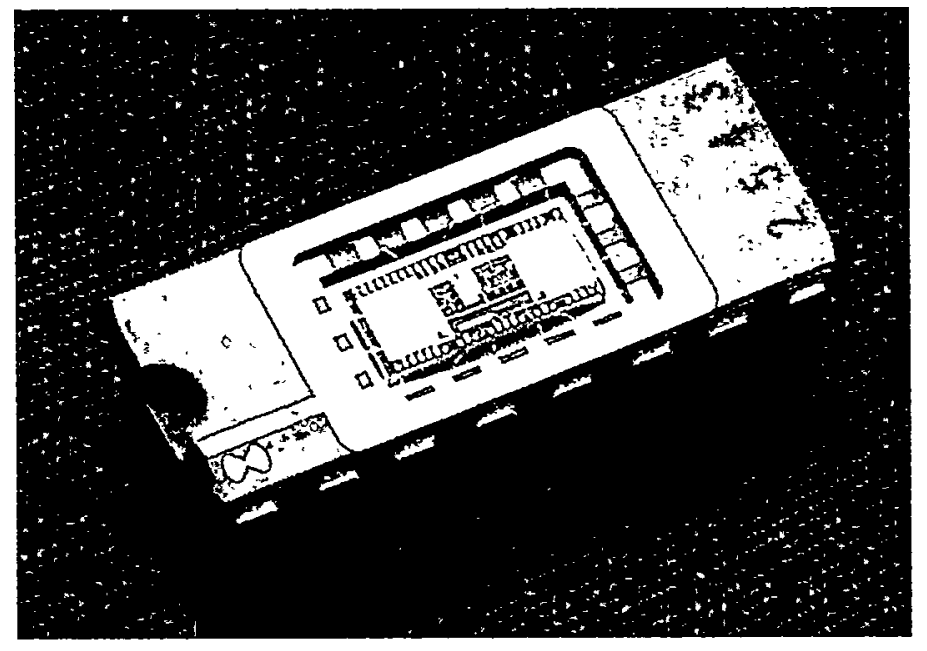

Figure 9. The Sandia Robust Hydrogen Sensor packaged as a 16 pin Dual Inline Package.

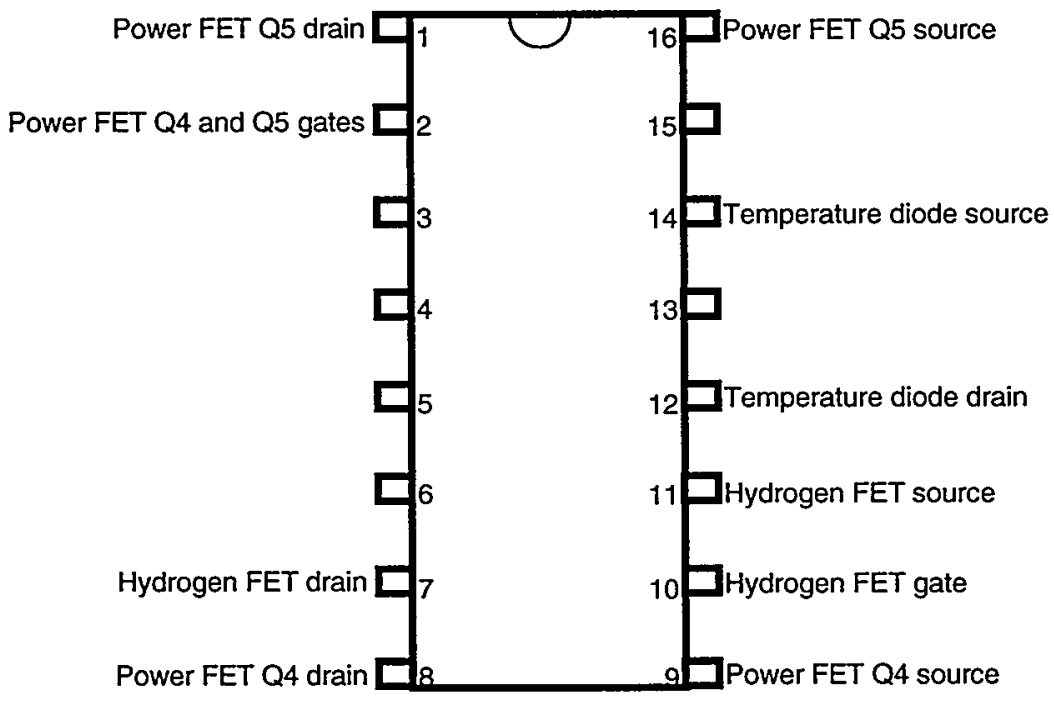

Figure 10. Pin Designations for the TA770 (16 pin DIP) Sandia Robust Hydrogen Sensor. 


\section{Circuit Design}

The Hydrogen Sensor Board had several main functions: hydrogen FET power and signal conditioning, power FET (temperature control) power and conditioning and a timing circuit. The board was separated into two sections - hydrogen FET side and power FET side. Each board section required its own power and its own ground. Prior knowledge and circuitry were used whenever available.

The Hydrogen Sensor Board functions were as follows:

Hydrogen FET side of the circuit board

a. Receive power pulse from the telemetry/data acquisition system.

b. Generate acceptable voltage and current to power the hydrogen FET.

c. Scale the hydrogen FET output voltage to match the data acquisition system input requirement.

d. Provide power FET heater circuit turn on signal at trailing edge of the power pulse from the telemetry/data acquisition system.

\section{Power FET side of the circuit board}

a. Condition Power from an external source.

b. After receiving a signal from the hydrogen FET side of the board, bring the Sandia Robust Hydrogen Sensor chip up to a prescribed temperature (typically $90^{\circ} \mathrm{C}$ ) for a specific length of time, and then return to room temperature (remove heater power).

Several circuit designs for using the Sandia Robust Hydrogen Sensor were available from past applications. Portions of these designs were used in this design. One circuit in particular is used extensively by Sandia's Microsensor R\&D Department for testing and calibrating the Sandia Robust Hydrogen Sensor (version TA770). This design incorporated circuitry to accommodate a wide variation in the hydrogen FET threshold voltages. The hydrogen FET threshold voltage varies from chip to chip, and wafer to wafer.

A previous project in the Integrated Nuclear Material Management (INuMM) program had designed a circuit for use with their battery powered measurement system. Their circuit was designed to use a few milliamps of current as opposed to the Microsensor R\&D Department system where current was not a concern. The batterypowered circuit did not include any temperature control circuits because it was an ultra low power system incapable of providing the current levels required by the power FETs. Because, power and circuit area were limited, this circuit used a voltage doubling circuit to double the $3.6 \mathrm{~V}$ battery voltage insuring that the hydrogen FET could always be operated at its threshold voltage. 
Circuit elements were used from both designs in addition to new elements required by the present application. Several major constraints had impact on the design elements and are listed in Table 2.

Because this circuit required the use of the on-chip heaters the circuit was split into two sections - one for the hydrogen FET side and one for the temperature control side. The hydrogen FET side used the telemetry/data acquisition system battery power while the Power FET side used an external power supply. This posed a potential problem since all the circuitry on the $\mathrm{H} 2$ sensor chip shared a common substrate making the substrate a common potential.

One impact of this requirement is that using the hydrogen FET by itself is fine, but using two different power supplies is only good if you don't turn on the protection diode. In this design, voltage is doubled by using a series capacitor technique. This provides very limited current capability. If the protection diode turns on and current is lost to the power side of the circuit, the hydrogen FET will not be properly biased and a hydrogen measurement cannot be made.

\section{Table 2. Design Constraints}

\section{Constraint}

- Low power draw - $<2.5 \mathrm{~mA}-$ less if possible

- Only 3.6 volts available.

- Single sided power supply

- Temperature control required as an option

- Temperature circuit must turn on (for controlled time) after data acquisition system reads hydrogen FET

\section{Design impact}

\section{Previous Design inputs}

Part of the circuit had to use low
power parts

Need to generate higher voltage

OpAmps must be biased off ground and must operate rail-torail.

Need external power supply for temperature side of circuit

Not compatible with need to have low power draw.

A timer must be present in circuit
Single shot doubler circuit was

used

Similar to previous design but with max current \& timer control added 
This means that the hydrogen FET side and the temperature control side must be completely isolated from each other (power and ground). Alternatively, the external power supply (on the power side) must be on at all times to prevent the protection diode from being turned on by the hydrogen FET side of the circuit. It was found through testing that it was impossible to isolate the hydrogen FET and power FET grounds forcing power to be applied to the power terminals at all times even if the power FETs are not operated.

Figure 11 presents the complete Hydrogen Sensor circuit design. This circuit can be broken down into four key sub-circuits:

1. A constant current source for biasing the FET.

2. A zero and scale adjustment.

3. Voltage doubling for operation from a $3.6 \mathrm{~V}$ battery.

4. Triggered heater control.

These sub-circuits will each be discussed separately in detail in subsequent sections.

A parts list for the Hydrogen Sensor Board is presented in Table 3. 


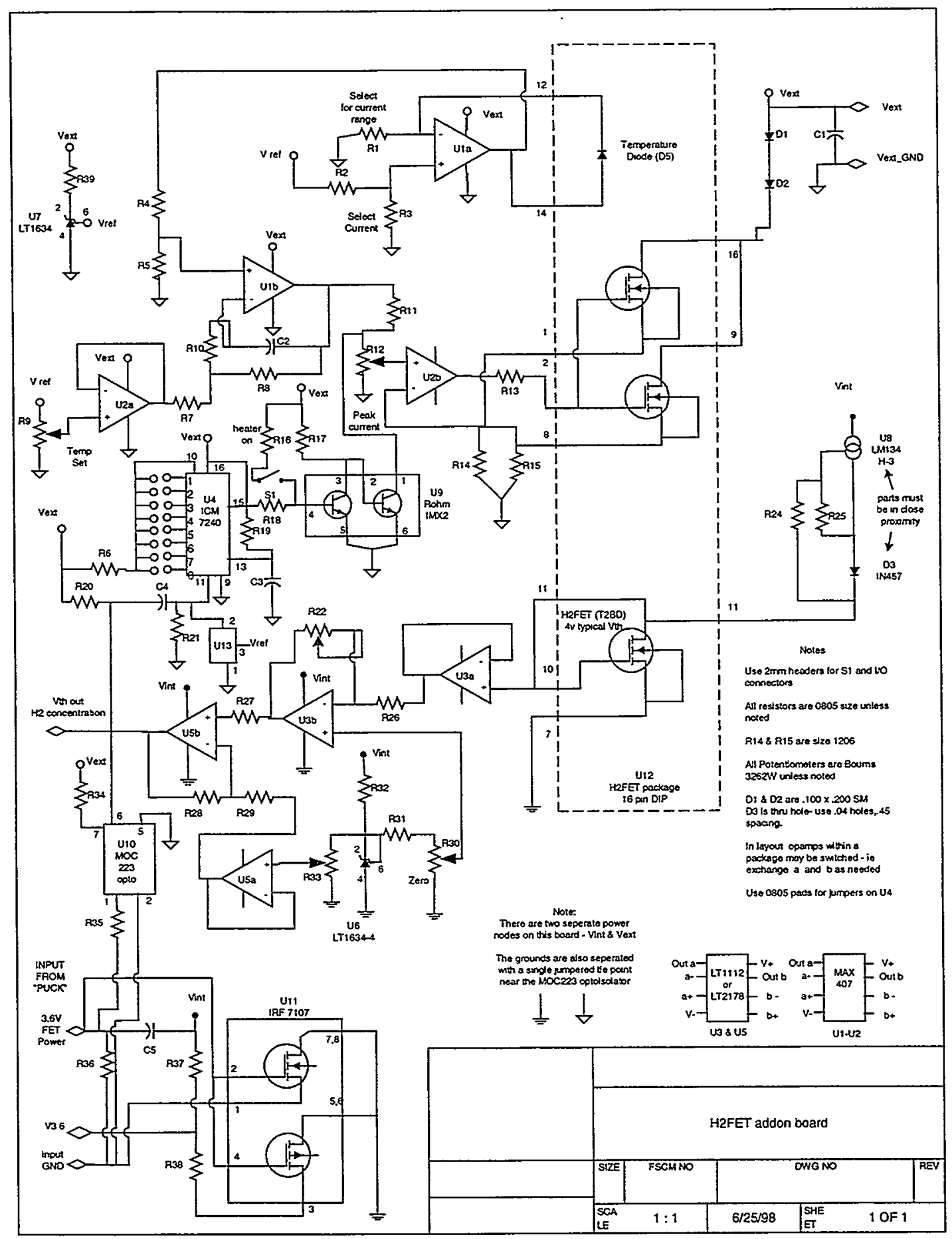

Figure 11. Electrical Schematic for the Hydrogen Sensor Board 


\section{Table 3. Parts List for the Hydrogen Sensor Board}

\begin{tabular}{|c|c|c|c|}
\hline Part Designation & Part Description & Part number & Supplier \\
\hline $\mathrm{U} 1$ and $\mathrm{U} 2$ & MAX407 or LT1112 or LT2178 & MAX407ESA & Maxim or Linear Technology \\
\hline U3 & MAX407 opamp & MAX40TESA & Maxim \\
\hline U4 & ICM7240LE (IPE can be used) timer & ICM7240UE & Maxim \\
\hline U5 & MAX407 opamp & MAX407ESA & Maxim \\
\hline $\mathrm{U} 6$ and $\mathrm{U} 7$ & LT1634 4 volt reference & $\begin{array}{l}\text { LT1634AIS8- } \\
4.096\end{array}$ & Linear Technology \\
\hline U8 & LM134H-3 current source - set to approx $100 \mu \mathrm{A}$ & LM134H-3 & National \\
\hline U9 & IMX2 bipolar transistors & $\mathbb{M X} 2$ & Rohm \\
\hline U10 & MOC223 opto isolator & & Motorola \\
\hline U1l & IRF7105 power MOSFET & IRF7105 & International Rectifier Corp \\
\hline \multirow[t]{2}{*}{ U12 } & Sandia Robust Hydrogen Sensor - TA770 & TA770-001 & Sandia National Labs \\
\hline & $\begin{array}{l}\text { ALL RESISTORS ARE SIZE } 0805 \text { UNLESS } \\
\text { SPECIFIED }\end{array}$ & $\begin{array}{l}\text { Resistors are } \\
10 \% 200 \mathrm{ppm} \\
\text { unless specified }\end{array}$ & $\begin{array}{l}\text { Any manufacture is } \\
\text { acceptable if they meet the } \\
\text { specs }\end{array}$ \\
\hline RI & Select for desired diode current - approx $4.7 \mathrm{k}$ & & Any \\
\hline $\mathrm{R} 2$ and $\mathrm{R} 3$ & $47 \mathrm{k}$ & $1 \% 25 \mathrm{ppm}$ & Any \\
\hline R4 & short & & Any \\
\hline R5 & Open & $\cdot$ & Any \\
\hline R6 & $10 \mathrm{k}$ - not critical - used as pullup & & Any \\
\hline R7 & $10 \mathrm{k}$ & $1 \%$ 25ppm & Any \\
\hline R8 & $220 \mathrm{k}$ & $1 \% 25 \mathrm{ppm}$ & Any \\
\hline R9 & 100k pot - not critical - trade off against current reqmts & Boums 3262 & Vishay(preferred) or Bourns \\
\hline R10 & short & & Any \\
\hline R11 & $10 \mathrm{k}$ & & Any \\
\hline $\mathrm{R} 12$ & $100 \mathrm{k}$ pot & & Vishay(preferred) or Boums \\
\hline $\mathrm{R} 13$ & lk- not critical & & Any \\
\hline $\mathrm{R} 14$ & 2.20 hms - size 1206 - current sense resistor $-5 \%$ & $\mathrm{P} 2.2 \mathrm{BCT}$ & Panasonic \\
\hline $\mathrm{R} 15$ & $2.20 \mathrm{hms}$ - size 1206 - current sense resistor $-5 \%$ & $\mathrm{P} 2.2 \mathrm{BCT}$ & Panasonic \\
\hline $\begin{array}{l}\mathrm{R} 16, \mathrm{R} 17 \text {, and } \\
\mathrm{R} 18\end{array}$ & $4.7 \mathrm{k}$ & & Any \\
\hline R19 & $220 \mathrm{k}$ timer charge resistor & $1 \% 100 \mathrm{ppm}$ & Any \\
\hline R20 & $10 \mathrm{k}$ & & Any \\
\hline $\mathrm{R} 21$ & $100 \mathrm{k}$ & & Any \\
\hline $\mathrm{R} 22$ & IM pot (high quality - stake after setting) & Bourns 3262 & Vishay(preferred) or Bourns \\
\hline R23 & Not used - open & & Any \\
\hline R24 & $15 \mathrm{k}$ & $1 \%$ 25ppm & Any \\
\hline R25 & $1.5 \mathrm{k}$ & $1 \% 25 \mathrm{ppm}$ & Any \\
\hline R26 & $100 \mathrm{k}$ & $1 \% 25 \mathrm{ppm}$ & Any \\
\hline $\mathrm{R} 27$ & Short & & Any \\
\hline $\mathrm{R} 28$ and R29 & $560 \mathrm{k}$ & $1 \% 25 \mathrm{ppm}$ & Any \\
\hline $\mathrm{R} 30$ & IM pot (high quality - stake after setting) & Bourns 3262 & Vishay(preferred) or Bourns \\
\hline $\mathrm{R} 31$ & Short & & Any \\
\hline R32 & $87 k$ & . & Any \\
\hline R33 & IM pot (high quality - stake after setting) & Boums 3262 & Vishay(preferred) or Boums \\
\hline R34 & Not used & & \\
\hline R35 & $2.7 \mathrm{k}$ & & Any \\
\hline $\mathrm{R} 36$ & IM-not critical & & Any \\
\hline R37 & $1 \mathrm{M}-$ not critical & & Any \\
\hline R38 & $1 k-10 k$ & & Any \\
\hline R39 & 560 ohms & & Any \\
\hline
\end{tabular}




\section{Table 3. Parts List for the Hydrogen Sensor Board - Continued}

\begin{tabular}{|c|c|c|c|}
\hline Part Designation & Part Description & Part number & Supplier \\
\hline $\mathrm{DI}$ & Not used - use a jumper & & \\
\hline D2 & Not used - use a jumper & & \\
\hline \multirow[t]{2}{*}{ D3 } & 1N457 & & Any \\
\hline & $\begin{array}{l}\text { ALL CAPACITORS ARE SIZE } 1206 \text { UNLESS } \\
\text { SPECIFIED }\end{array}$ & & \\
\hline $\mathrm{Cl}$ & $10 \mu \mathrm{F}$ - not critical - EIA size $C$ & & Any \\
\hline $\mathrm{C} 2$ & Not used - open - use to control response or oscillation & & Any \\
\hline $\mathrm{C} 3$ & $10 \mu F$ - controls timing - ELA size $C$ & & Any \\
\hline $\mathrm{C} 4$ & $.1 \mu \mathrm{F}-$ not critical - & & Any \\
\hline C5 & $68 \mu \mathrm{F}$ - controls current available during doubling-size $\mathrm{C}$ & & Any \\
\hline Sl & External switch & & Any \\
\hline
\end{tabular}

\section{Current Source}

The current source used on the board is a LM134 which is set to approximately $100 \mu \mathrm{A}$. The circuit for the current source is shown in Figure 12. Diode D3 and resistors R24, R25 form a temperature compensation network for the LM134. The selection of R24 and R25 is based on calculations from the LM134 data sheet and allow the Vtc of the diode to create a current which compensates for the change in the LM134 current over temperature (provided R24 and R25 are correctly selected).

There are several problems with this circuit. If you need to adjust the current (which you might want to do to adjust the temperature coefficient of the hydrogen FET) then you need to change one of the compensation resistors but, if you do that, then the temperature compensation is no longer valid. Table 4 shows how the temperature coefficient of the current source varies with a change in R24.

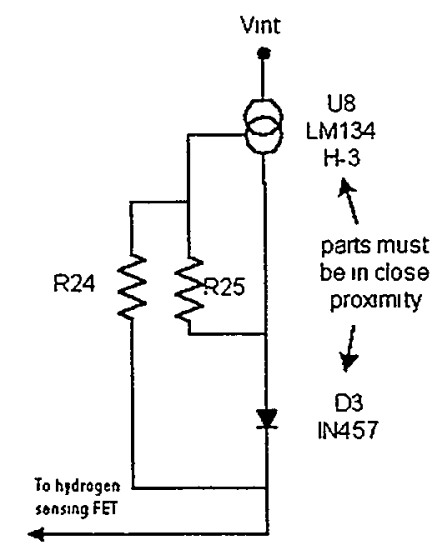

Figure 12. Constant Current Source Circuit. 


\section{Table 4. Effect of R24 Resistance on the Current Source Temperature Coefficient}

\begin{tabular}{ccc} 
R25 $(\mathbf{k ~ o h m s})$ & I current source $(\mu \mathbf{A})$ & $\begin{array}{c}\text { temperature } \\
\text { coefficient }(\mu \mathbf{A} / \mathbf{C})\end{array}$ \\
\hline 1.5 & 89.6 & -.0002 \\
1.4 & 92.87 & .0106 \\
1.3 & 96.59 & .0231 \\
1.2 & 100.1 & .0376 \\
1.1 & 106 & .0548 \\
.9 & 119.7 & .1 \\
.8 & 129. & .1322
\end{tabular}

Note that for optimal compensation, the ratio of R24 to R25 is 10:1. When you drift away from that ratio, the temperature coefficient of the current source gets worse. For small shifts away from the ideal ratio the temperature coefficient remains reasonable but for larger changes in the ratio (.8k R25 vs. $15 \mathrm{k}$ R24) the temperature coefficient is objectionable and would create problems if the environment temperature varied more than 10 degrees from nominal. In practice, we did not adjust the current so the circuit values could remain at the correct ratio. However, if the current needs to be adjusted then you would need to reselect values for the two resistors before using the circuit.

A second problem with this current source is that if fast temperature changes are anticipated then the diode and LM134 will change temperature at different rates causing a large transient effect. Because of the way our system was to be used (inside a second larger system) fast temperature changes were unlikely, and hence, the LM134 was a workable solution. ' One cure for this problem is to use a diode (or transistor junction) which is thermally tied to the LM134. This is a typical approach and it is surprising that the LM134 does not include an internal diode for this purpose. Experimental data shows that this solution can greatly reduce transient effects compared to using the two devices mounted to a circuit board [Jenkins and Anderson, 1999].

An alternate board was designed to address the above problem and uses a current source which utilizes a opamp to regulate the current through the hydrogen FET rather than use the LM134 current source. The version 2 circuit will be discussed in Appendix B.

Several other factors need to be mentioned in this section. One problem with the hydrogen FETs that were used in this project is that they have at threshold voltage of around $3 \mathrm{~V}$ (at $25^{\circ} \mathrm{C} 0 \mathrm{ppm} \mathrm{H}_{2}$ ). This means that a minimum voltage needed to run this 
circuit is the threshold voltage plus the voltage required by the current source. For the standard circuit, this is about:

$3 \mathrm{~V}$ (threshold voltage $)+0.9 \mathrm{~V}(\mathrm{LM} 134$ current source $)+0.6 \mathrm{~V}($ diode $)=4.5$ volts.

If you use the alternate circuit then the minimum is:

$3 \mathrm{~V}($ threshold voltage $)+0.5 \mathrm{~V}$ (current sense $)=3.5$ volts.

Either way, the required voltage is too high to be run from a battery system limited to 3.6 volts. This is why the circuit contains a voltage doubler. Fortunately, the threshold voltage decreases with increasing hydrogen concentration. A solution for the normal, zero hydrogen condition remains a solution throughout the sensors operating range.

Some hydrogen FETs have been produced with threshold voltages near 2.6 volts, but these were unavailable for this sensor board development.

\section{Gain Block and Level Adjustment}

The hydrogen FET output signal conditioning consists primarily of low power opamps used to amplify the hydrogen FET threshold voltage and level shift the signal into the proper range for use by the data acquisition system. The input required by the data acquisition system is 0.4 to 1.4 volts. The output from a typical hydrogen FET is from 3 to 2.6 volts over the range of interest. The average gain is 2.5 and includes a 1:1 a signal inversion. Figure 13 shows the circuit used to accomplish these requirements.

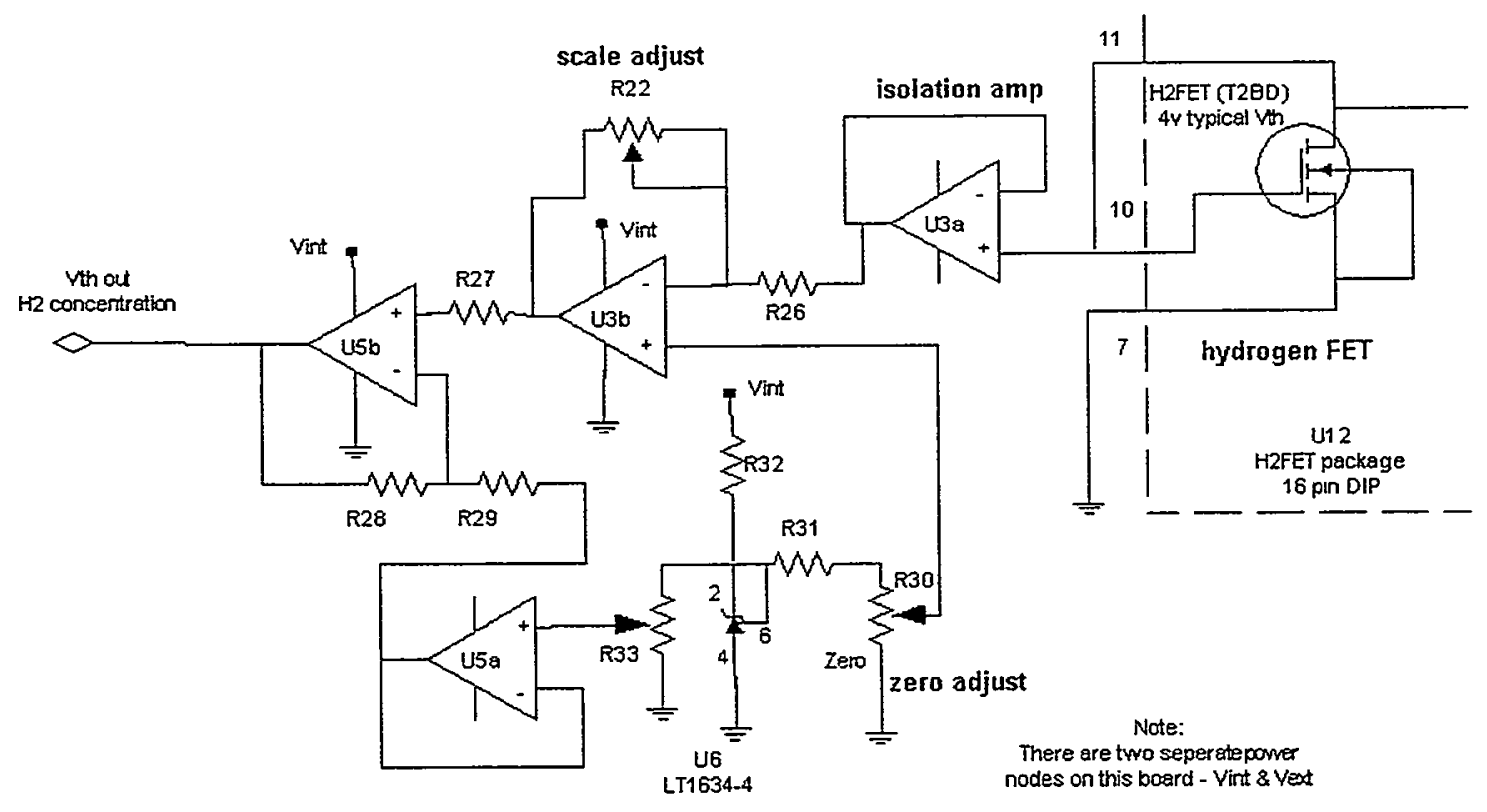

Figure 13. Zero and Scale adjusting circuit 
A current produced by the previously discussed current source (U8) feeds the hydrogen FET whose drain is shorted to its gate. This configuration causes the hydrogen FET to bias at its threshold voltage for that specific current. This current must be selected to be near the zero temperature coefficient point for the FET or the threshold voltage will change significantly with temperature.

Since the hydrogen FET is very sensitive to a change in its drive current, a buffer is used to isolate the hydrogen FET current from the processing circuits. U3a is configured as a high impedance buffer, and prevents any loss or change of current through the hydrogen FET due to loading. The output from U3a is the hydrogen FET threshold voltage and needs to be scaled, shifted and inverted.

The second stage (U3b) accomplishes all of the 3 goals, it 1) provides an initial level shift, 2) provides gain and 3) provides signal inversion. The output stage (U5b) is configured as a non-inverting level shifter.

A voltage reference is provided in order to accurately set the references for the level shifting operations. The LT1634 was selected because it is a good compromise between accuracy and current consumption. Since the signal conditioning side of the Hydrogen Sensor Board was to run on a current under $2.5 \mathrm{~mA}$ the components need to be low current versions. The LT1634 is not as good as a higher current source, but it only draws $40 \mu \mathrm{A}$ plus use current. The LT1634 is set up for about $40 \mu \mathrm{A}$ with about $4 \mu \mathrm{A}$ being drawn for each of the level shift pots. The reference level for the output shifter is buffered by U5a in order that the set-point at the R33 wiper is not changed when R33 is changed. This is not necessarily required, but without it, the reference would change and make adjustment somewhat more difficult. This needs to be traded off against the cost of the current used by the buffer but in this case the opamps are duals and very low current.

Setting the shift levels and gain requires several iterations and the process is reviewed in the next few paragraphs. The objective is to map the output from the hydrogen FET to the input range required by the data acquisition system. Since each hydrogen FET can be different we will review as an example a hydrogen FET which has a response to hydrogen concentration of $3.0 \mathrm{~V}$ to $2.6 \mathrm{~V}$. This voltage variation needs to be mapped to the 0.4 to 1.4 volts required by the data acquisition system. This gives a gain of 2.5 with an inversion. Table 5 below shows the input and output form each of the signal processing stages with the indicated reference values and a U3b gain of 1.25. 
Table 5. Voltages through the gain block and level shifters

\begin{tabular}{ccc}
$\begin{array}{c}\text { Threshold } \\
\text { Voltage, Vth }\end{array}$ & $\begin{array}{c}\text { U3b output } \\
\text { (gain+shift) } \\
\text { (U3a +input) }\end{array}$ & $\begin{array}{c}\text { U5b output } \\
\text { (final output) } \\
\text { Ref }=\mathbf{2 . 1 5} \mathbf{~} \mathbf{7 5}\end{array}$ \\
\hline $3.00 \mathrm{v}$ & $1.08 \mathrm{v}$ & $.41 \mathrm{v}$ \\
2.90 & 1.21 & .66 \\
2.80 & 1.33 & .91 \\
2.70 & 1.45 & 1.16 \\
2.6 & 1.58 & 1.41
\end{tabular}

In practice, the first reference (the ref into $\mathrm{U} 3 \mathrm{~b}+$ ) is set to a level which will guarantee that over the input range from the hydrogen FET buffer the output from U3b will not get too close to either rail. The gain is then adjusted to yield the required output range, followed by an adjustment of the U5b reference (U5a output) which moves the overall curve to the $0.4 \mathrm{~V}$ starting point.

In general it takes several iterations to get the gain set to the proper level. A variable resistor was substituted for the hydrogen FET to do this adjustment. This resistor was adjusted to simulate whatever range a particular hydrogen FET exhibited. This could also be accomplished using a power supply at the input but the resistor produces the same conditions as the hydrogen FET and it can be handily substituted when needed.

Since the circuit is intended to function with a single ended supply, all the opamps must be biased off ground. This means that you need to use opamps which handle near rail to rail inputs and outputs.

\section{Voltage Doubling}

In order to operate off of a lithium battery supplying 3.6 volts while being able to bias the hydrogen FET to a threshold voltage of as much as 4 volts (plus the current source voltage drop) required a circuit to increase the supplied battery voltage. Rather than use a DC to DC power converter which would consume too much power, a voltage doubling circuit using two switching FETs (U11) and a capacitor (C5) to temporarily increase the voltage supplied to the constant current source and the zero and scaling circuit to about 7.2 volts.

Figure 14 shows the voltage doubling circuit. The capacitor was charged to $3.6 \mathrm{~V}$ during the period between the polling of the Hydrogen Sensor Board by the telemetry system. Charging is accomplished through R37 from a constant 3.6 volts applied by the 
telemetry system. When the telemetry system switches its polling line (labeled 3.6V FET power) from 0 to 3.6 volts, the voltage doubling circuit reacts to switch the capacitor in series. The current demand is small, between 100 and $200 \mu \mathrm{A}$, and the time of operation is short, on the order of 100 milliseconds. Using a simple constant current model for the discharge would yield a droop of 0.3 volts for $200 \mu \mathrm{A}$ constant current and a $68 \mu \mathrm{F}$ capacitor. This would mean a low voltage of about 6.9 volts, still high enough to guarantee proper circuit operation.

Also shown in the figure are 3 components that are actually part of the timer circuitry discussed in the next section. These components (U10, R34 and R35) form an opto isolator circuit used to trigger the heater timer which provide total isolation of the heater / timer from the measurement circuits. The isolator current is taken from the 3.6 volt side of the circuit in order not to draw any current from the doubling capacitor. The isolator draws about $1.5 \mathrm{~mA}$ whenever the $3.6 \mathrm{~V}$ FET Power is high.

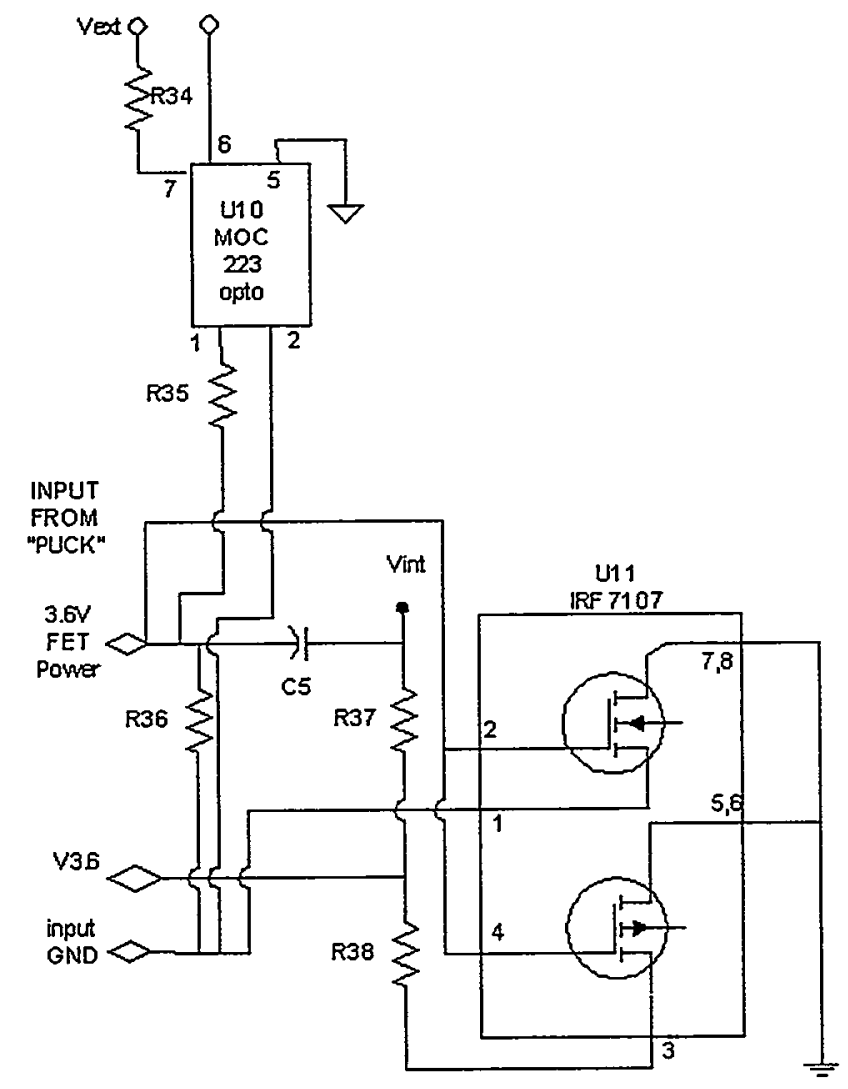

Figure 14. Voltage Doubling Circuit. 


\section{FET Heater Control}

The Hydrogen Sensor Board included a versatile heater control circuit. The Sandia Robust Hydrogen Sensor includes as part of the integrated circuit two power FETs and a diode (D5) used as a temperature sensor. The power FETs are driven to heat the Sandia Robust Hydrogen Sensor to $90^{\circ} \mathrm{C}$ with feedback control provided by the diode.

In a typical application, heating the Sandia Robust Hydrogen Sensor gives more rapid response to changing hydrogen levels. It was originally believed that it might be necessary to heat the Sandia Robust Hydrogen Sensor intermittently in order to have it correctly measure even a slowly changing hydrogen level. During calibration testing, it was found that the heaters were unnecessary for the anticipated application that would track slowly changing hydrogen levels over several months.

The heater circuit monitors (via U10 opto-isolator shown in Figure 11 and 14) the "3.6v FET Power" line from the telemetry system. When the heater circuit senses the power line falling from 3.6 volts to 0 volts, it switches on the heaters for a period of time selected by jumpering the correct inputs of the timer chip (U4). The heaters can be manually switched on by closing switch S1. The peak current drawn by the heaters can be limited by adjusting R12. The heaters are powered by external power source set at 7.2 volts.

The heater control circuit (Figure 15) consists of 5 parts:

1. a voltage reference (U9),

2. a temperature monitor (U1a, D5),

3. a control block (U1b, U2a),

4. a current limiter (U2b), and

5. a timer (U4, U9, U10, U13).

A voltage reference is needed for a number of functions. It is used to set the temperature reference point and to set the temperature diode current.

The temperature monitor consists of a diode on the hydrogen FET die and opamp Ula and it's associated resistors. The hydrogen FET die has 9 diodes available for temperature measurement and selection depends on what point on the die will be used to set the temperature. For this application diode D5 is used to monitor temperature.

The current through the monitor diode must be constant in order to provide a good measurement of temperature, otherwise Vbe would be a function of both temperature and current. The current control opamp uses a reference on its + input to fix the voltage across $\mathrm{R} 1$ which in turn fixes the current through the diode. The current used is about $10 \mu \mathrm{A}$ but is adjustable either by the resistive divider or by changing the value of $\mathrm{R} 1$. 


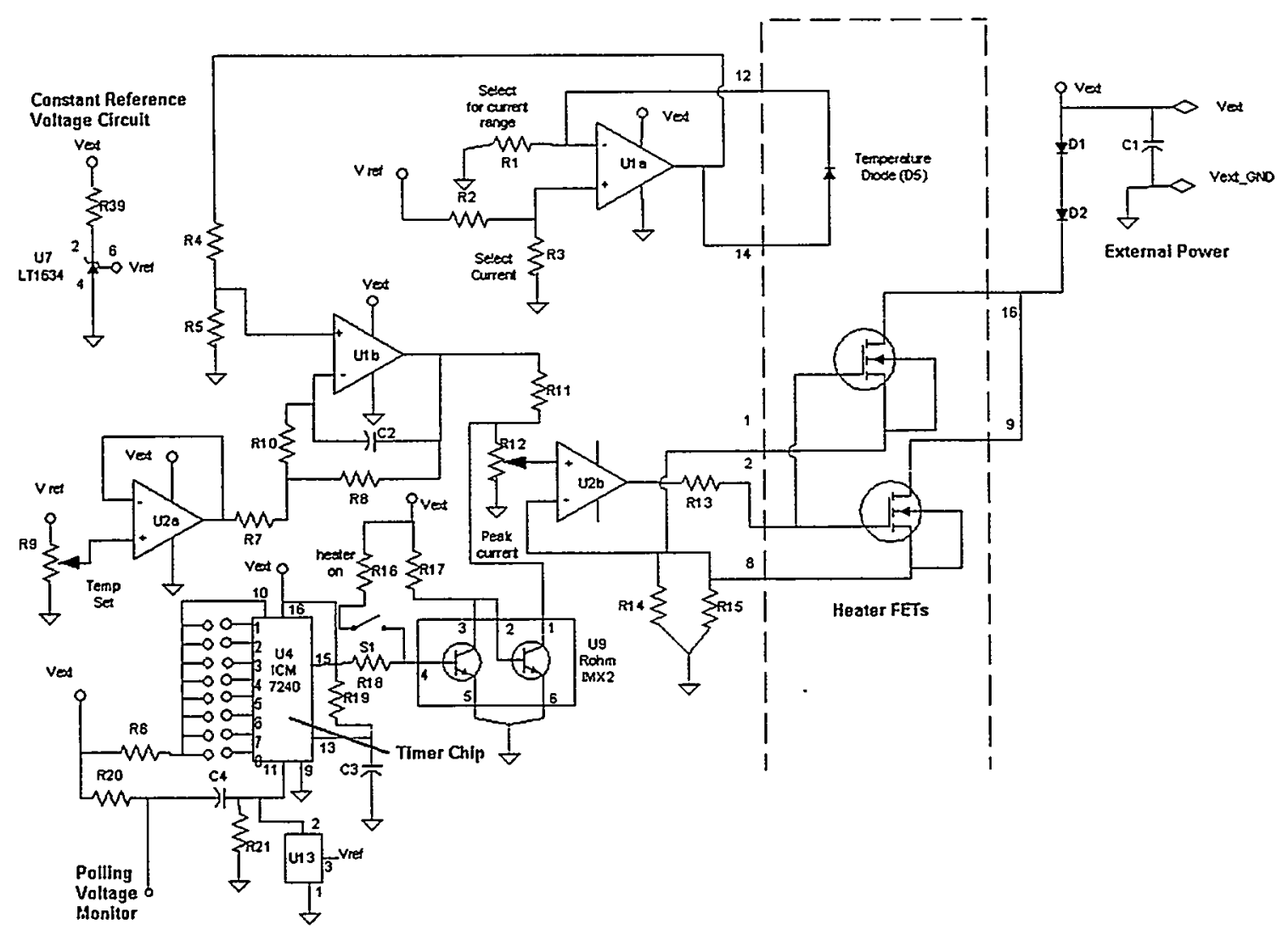

Figure 15. Heater Control Circuit.

The next part of the circuit is the control block. The section consists of U1b and $\mathrm{U} 2 \mathrm{a}$ and associated components. U2a is a buffer that accepts the temperature setpoint from R9 and passes it to the control amp U1b. The buffer is not strictly necessary, but it allows the current input to the control amp to be independent of the setpoint resistor. The control amp amplifies the difference between the temperature monitor and the temperature reference, and provides an output used to drive the heater FETs.

Components R7, R8, R10, and C2 control the gain and response of the system.

The output of the control block is run through a voltage to current controller which can be used to set the maximum current which will flow through the power FETs. The circuit insures that for any given supply voltage you can limit the max power dissipated by the FETs. The peak FET current can be adjusted by R12. Opamp U2b is configured as the current controller. Whatever voltage is on the wiper of R12 will appear across the parallel combination of R14/R15 due to the action of the opamp driving the FET gates to a level producing the voltage match.

The last part of the heater control section is the timer. The timer consists of U4, $\mathrm{U} 13, \mathrm{U} 9, \mathrm{U} 10$ and the associated resistors and capacitors. As discussed previously U10 is an opto isolator that provides the trigger input for the timer. Whenever there is voltage 
applied to the 3.6V FET power input (measurement side of circuit) U10 shorts the R20, $\mathrm{C} 4$ node to ground. This causes $\mathrm{C} 4$ to discharge. When the 3.6v FET power input returns to ground (the measurement side turns off) $\mathrm{C} 4$ will recharge producing a positive spike on timer pin 11, which sets the timer latch, initializing the timer period. U13 is a MAX63xx (a number of trigger voltages/devices can be used) reset chip used only to guarantee that the timer is in the off state on power up.

The heart of the timer is the ICM7240 (U4) timer chip. The timer chip consists of a 555 type timer and an integrated long chain divider. The basic timing period is set by R19 and C3 and is simply the RC time. In this application R19 is $220 \mathrm{k}$ ohms and C3 is $10 \mu \mathrm{F}$ giving a period of 2.2 seconds. Timer pins 1-8 are used to select which divider output is used as the final output. The allows a multiplier of 1 to 128 to be applied to fundamental timing period for a final timer output of 2.2 to 282 seconds. For this application a multiplier of 128 is selected to give a timer period of about $5 \mathrm{~min}$. When the timer is in the off state the voltage on R12 is clamped (by transistor 2 in U9) to ground preventing the heater from operating. When the timer is triggered, this voltage is released (U9 transistor 2 off), and the heater will power up and reach a regulation state. A switch port (S1) is provided which can be used to enable the heater for setup purposes.

\section{Board Layout and Interfaces}

The Hydrogen Sensor Board was implemented on a two-layer circuit board with parts mounted on one side only. The general arrangement is shown in Figure 16.

The Hydrogen Sensor Board may be operated from the telemetry system battery or from external power. Figures 17 and 18 show how connections are to be made according to the operating mode.

Note that external power must be applied even when operating the Hydrogen Sensor Board from the telemetry system battery power. This is because ground loops were discovered passing through the Sandia Robust Hydrogen Sensor substrate and the heater circuitry. By biasing the external power connection with 7.2 volts, the oscillations were defeated. If battery operation is desired, the heater circuit should be eliminated altogether which will then eliminate the ground loop. 


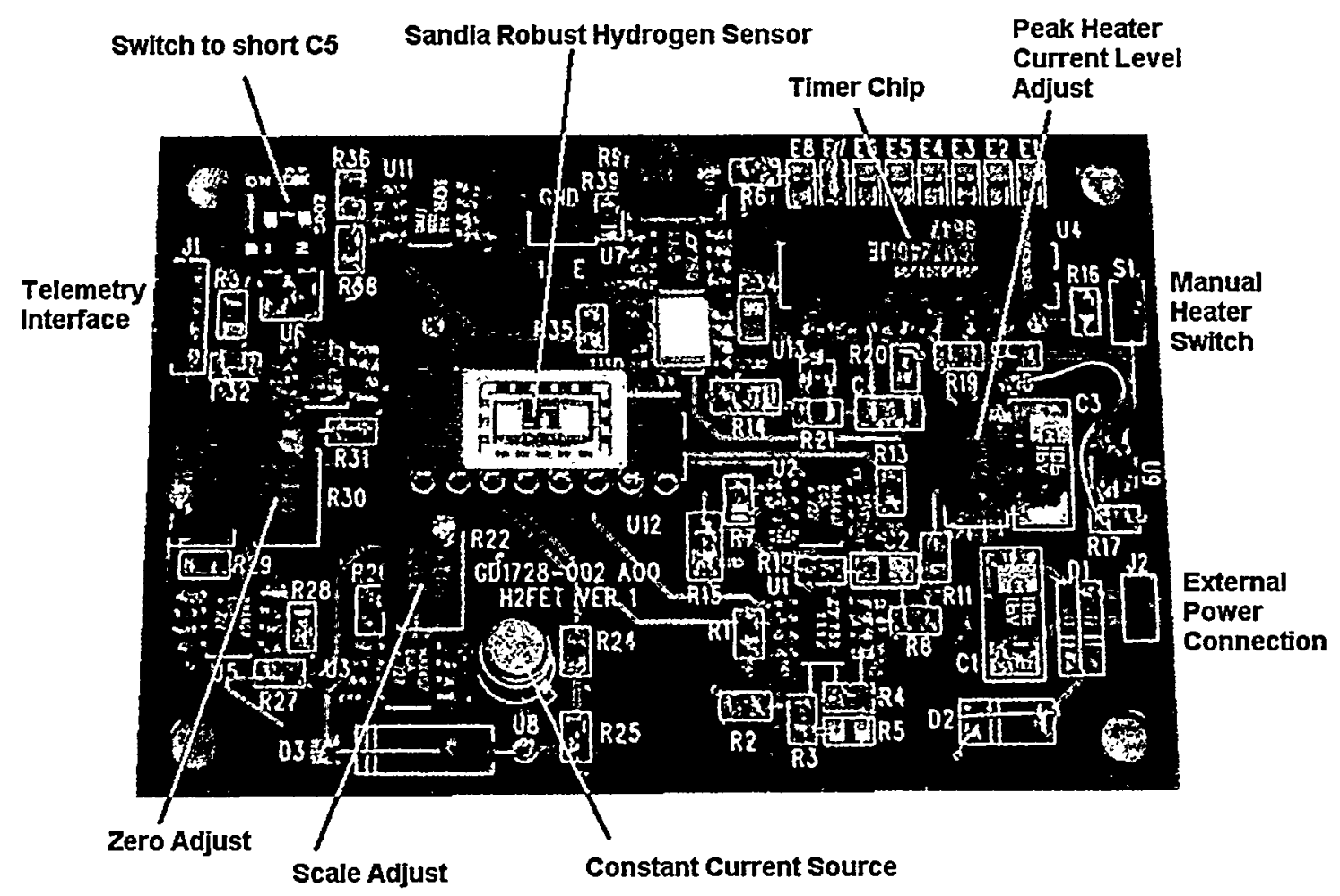

Figure 16. Hydrogen Sensor Board Layout

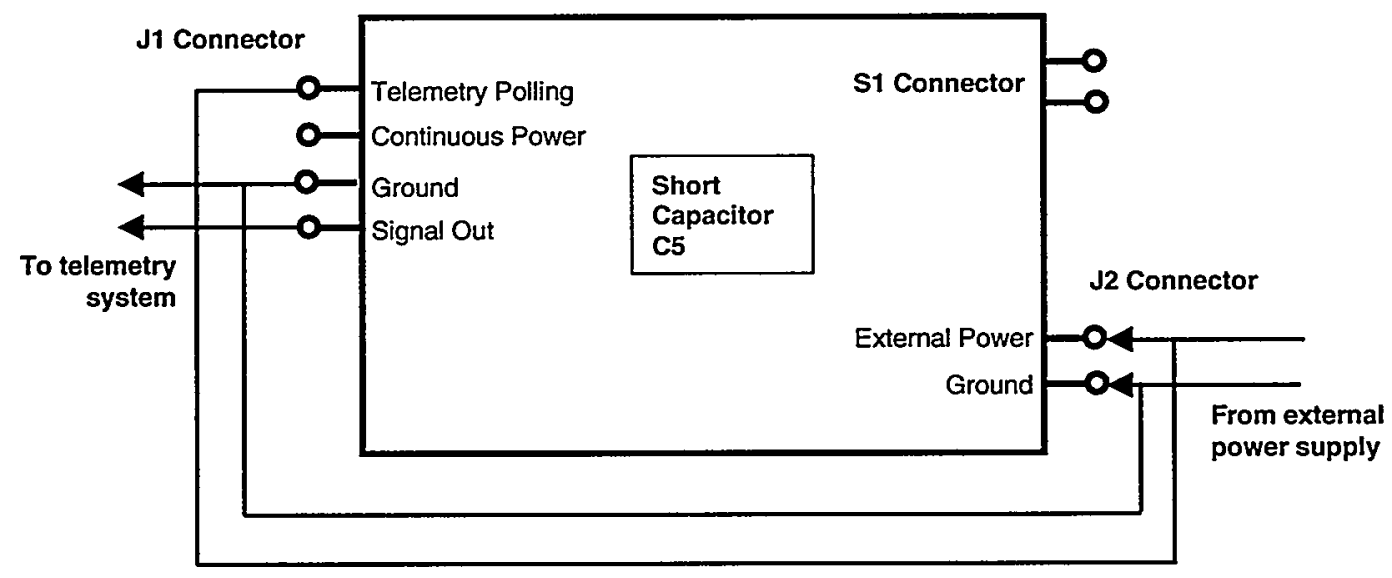

Figure 17. Connections for Powering the Hydrogen Sensor Board from an External Power Supply. 


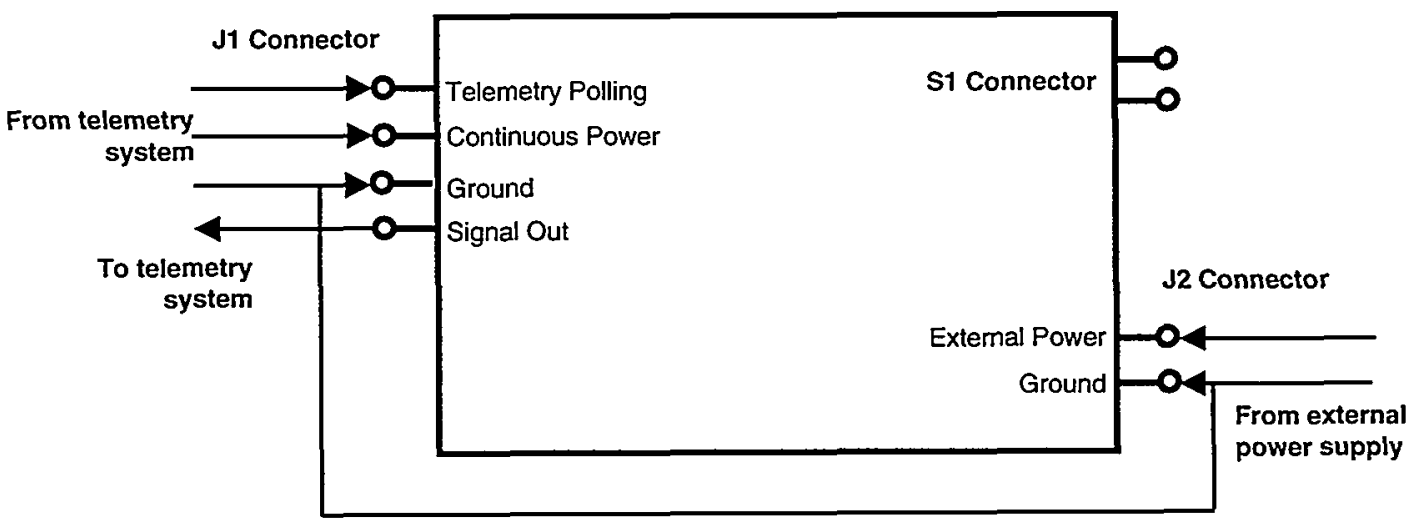

Figure 18. Connections for Powering the Hydrogen Sensor Board from the Battery Powered Telemetry System. External power must be applied to prevent oscillations in the output signal. 


\section{Calibration}

The calibration of the Hydrogen Add-On boards was conducted using a set of precision metering valves, nitrogen, oxygen, and hydrogen gas supplies, a sealed chamber, the add-on boards, and computer controlled voltmeters to read the add-on board output signal. Figure 19 illustrates the system.

\section{Calibration Data}

The add-on hydrogen board calibration series started on October 1, 1998 and ended on November 23, 1998. Table 6 lists the data files taken during the calibration tests.

Calibrations performed from October 1, 1999 to October 28, 1998 were to establish the operating characteristics of the boards and FETs. Several FETs were tried in board 1 until satisfactory results were achieved.

Once the FETs were selected and characterized, the signal conditioning zero and span were reset for the purposes of a test application. The calibration run on October 30, 1998 is the key calibration data.

After the October 30, 1998 calibration test, 3 calibration tests were performed where an INuMM ESP miniature data acquisition/telemetry system powered the FET circuit with the battery internal to the INuMM ESP.

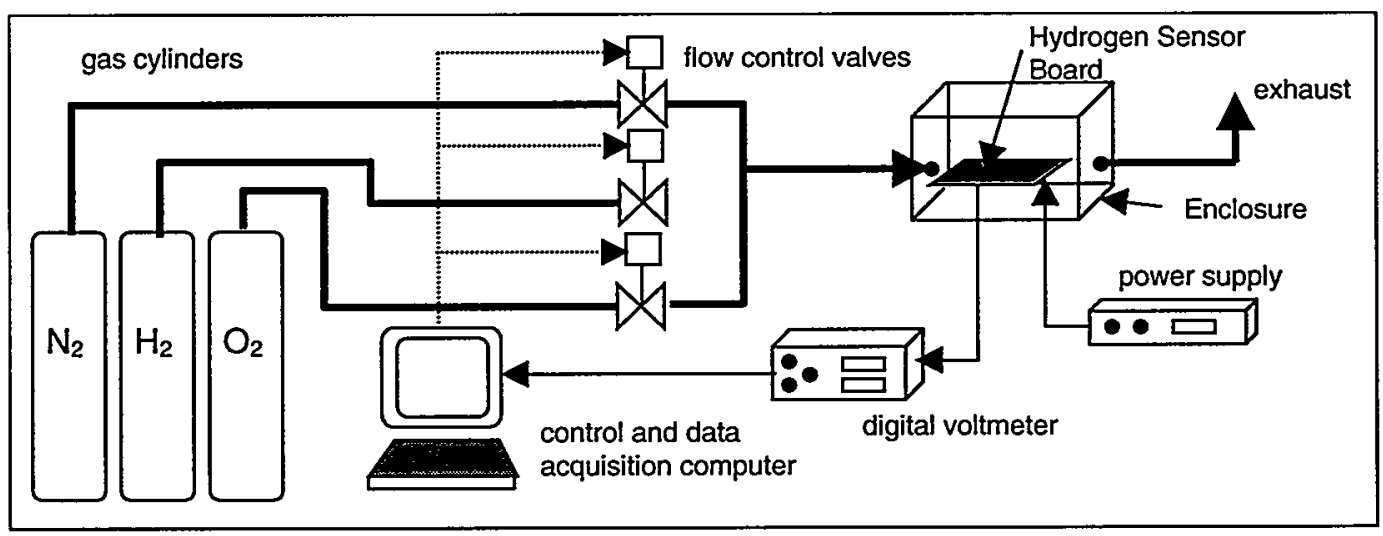

Figure 19. Calibration System 


\section{Table 6. Calibration Data Files}

\begin{tabular}{lcccl} 
Test Title & $\begin{array}{c}\text { Board 1 } \\
\text { FET }\end{array}$ & $\begin{array}{c}\text { Board 2 } \\
\text { FET }\end{array}$ & Heated & Notes \\
\hline GTB1_100198.001 & 2391 & $2541^{*}$ & Y & \\
GTB1_100298.001 & 2391 & $2541^{*}$ & & \\
GTB1_100798.001 & 2391 & $2541^{*}$ & Y & \\
GTB1_101298.001 & 2542 & $2541^{*}$ & Y & \\
GTB1_101398.001 & 2386 & $2541^{*}$ & & \\
GTB1_101498.001 & 2542 & $2541^{*}$ & Y & \\
GTB1_101598.001 & 2542 & $2541^{*}$ & & \\
GTB1_101698.001 & 2536 & $2541^{*}$ & Y & \\
GTB1_101698.002 & 2536 & $2541^{*}$ & Y & \\
GTB1_101898.001 & 2536 & $2541^{*}$ & & 44 hour test \\
GTB1_102198.001 & 2536 & $2541^{*}$ & & \\
GTB1_102298.001 & $2536^{*}$ & 2541 & & \\
GTB1_102398.001 & $2536^{*}$ & 2541 & & \\
GTB1_102698.001 & $2536^{*}$ & 2541 & & \\
GTB1_102898.001 & $2536^{*}$ & 2541 & Y \\
GTB1_103098.001 & $2536^{*}$ & 2541 & & \\
puck4c_2.xls & $2536^{*}$ & 2541 & \\
puck1116.xls & $2536^{*}$ & 2541 & \\
puck1123.xls & $2536^{*}$ & 2541 &
\end{tabular}

*Indicates the FET which was directly in front of the incoming gas flow

Note: all heated FETs were heated to $90^{\circ} \mathrm{C}$

Note: in the tests whose title begins with 'puck', the Hydrogen Sensor Board was powered via the battery in the telemetry package and used the voltage doubling circuitry on the Hydrogen Sensor Board. All other tests used a laboratory power supply to power the Hydrogen Sensor Board and bypassed the voltage doubling circuitry. 


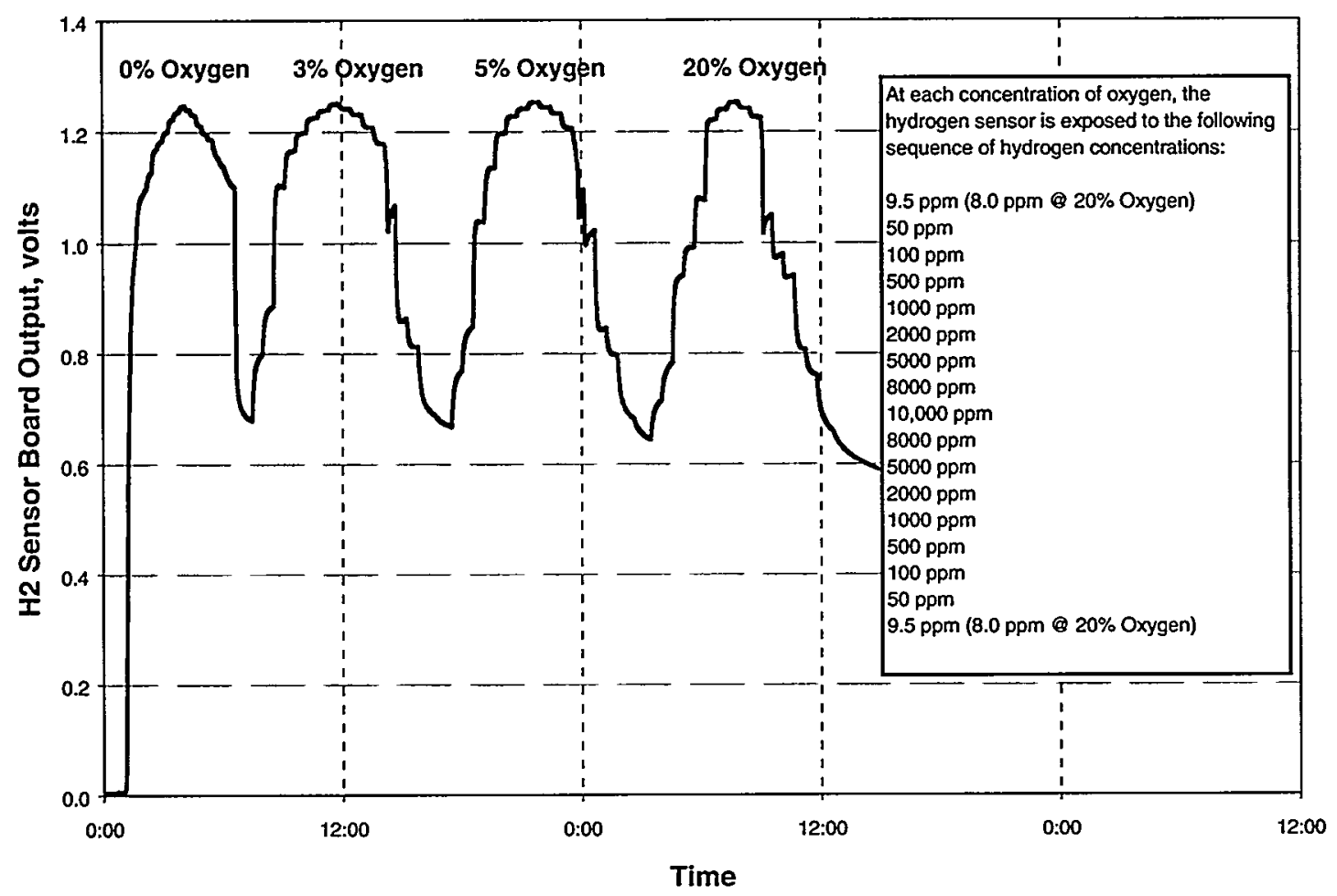

Figure 20. Typical Output Data for Hydrogen Sensor Board Calibration.

\section{FET Response to a Hydrogen/Nitrogen Atmosphere}

As discussed in the theory section, the response of the hydrogen FETs tested in a non-oxygen containing atmosphere should follow the equation:

$$
\frac{1}{\Delta \mathrm{V}}=\mathrm{K}_{1} \sqrt{\frac{1}{\mathrm{p}_{\mathrm{H}_{2}}}}
$$

Since we wish to determine the concentration of hydrogen, this equation is rearranged to:

$$
\sqrt{\mathrm{C}_{\mathrm{H} 2} \mathrm{P}_{\mathrm{amb}}}=\mathrm{K}_{3} \mathrm{~V}_{\text {out }}
$$

where now the partial pressure of hydrogen is expressed as the product of the hydrogen concentration and the ambient pressure. Note also that the output voltage from the hydrogen sensor board replaces the change in threshold voltage since the board output voltage is linearly related to the threshold voltage. 
Figure 21 shows the data for FET 2541 at hydrogen concentrations ranging from 9.5 to 10,000 ppm taken on October 30, 1998. The data shows marked non-linearities and does not follow theory. In fact, the curve fit shown requires that the concentration ratio data be transformed by a log function and then curve fitted to the voltage data by a $3^{\text {rd }}$ order polynomial. FET 2536 shows similar behavior.

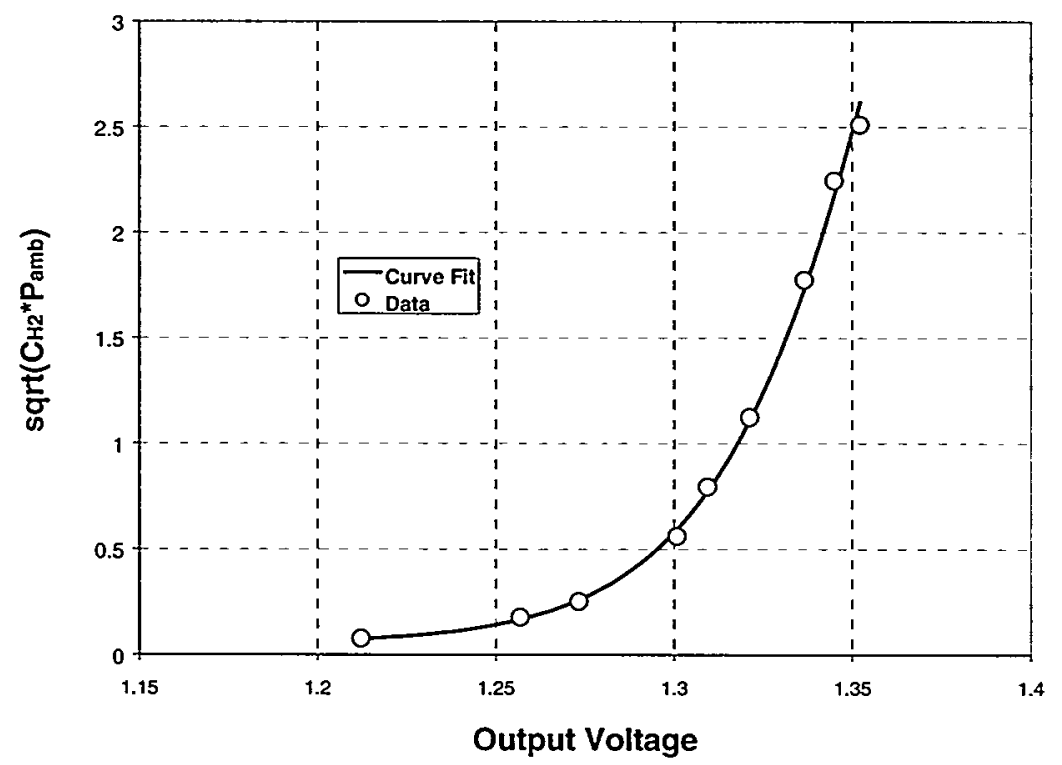

Figure 21. Response of Hydrogen FET 2541 to varying hydrogen concentrations in a nitrogen atmosphere.

\section{Effect of Oxygen on FET Response to Hydrogen}

When oxygen is present, the response of the FET by theory should follow the form of the equation:

$$
\frac{1}{\Delta V}=K_{2} \sqrt{\frac{\mathrm{p}_{\mathrm{O}_{2}}}{\mathrm{p}_{\mathrm{H}_{2}}}}
$$

Rearranging this equation similarly to the previous section, the hydrogen sensor board output can be related to the square root of the ratio of the hydrogen and oxygen concentration:

$$
\sqrt{\frac{\mathrm{C}_{\mathrm{H} 2}}{\mathrm{C}_{\mathrm{O} 2}}}=\mathrm{K}_{4} \mathrm{~V}_{\text {out }}
$$


Figure 22 shows the data for hydrogen concentrations from 9.5 to $500 \mathrm{ppm}$ in a nitrogen atmosphere also containing $3 \%, 5 \%$ and $20 \%$ oxygen. The data was taken on October 30,1998 . In this case, the data does show that at low hydrogen concentration, the response tends to follow theory and fitting a straight line.

However, when the data is extended over the entire range of hydrogen concentrations, see Figure 23, the response does not follow theory and is nonlinear. As it was in the case of no oxygen present, the response is logarithmic.

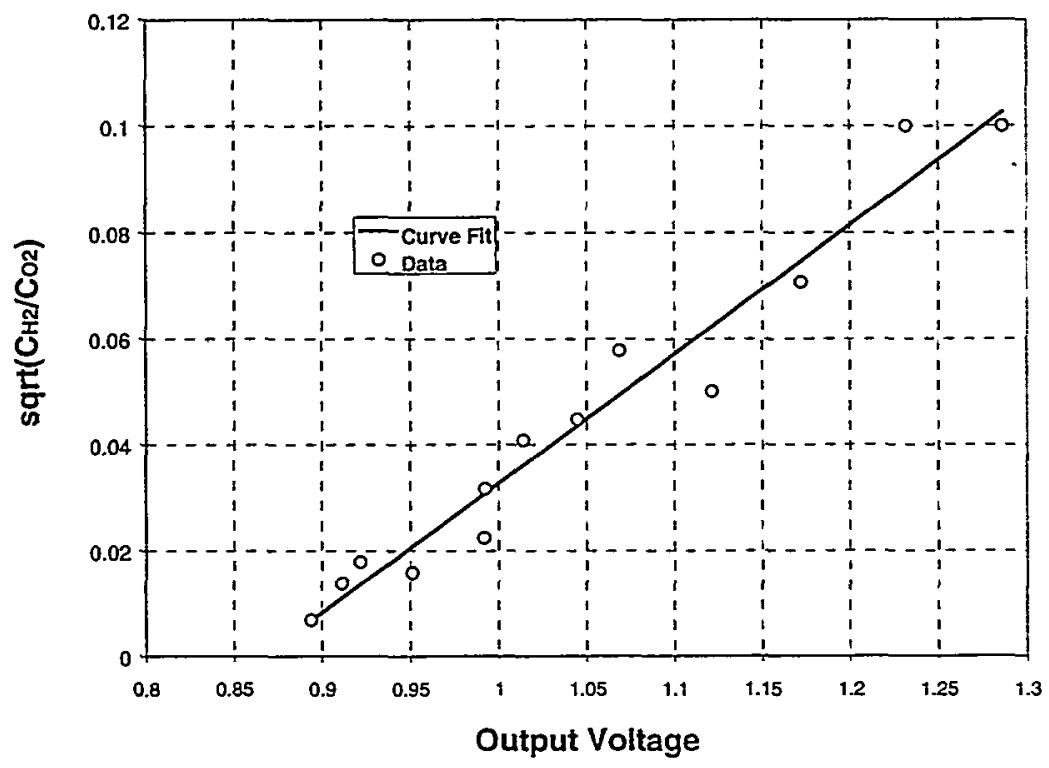

Figure 22. Response of Hydrogen FET 2541 to low hydrogen concentrations in a nitrogen/oxygen atmosphere 


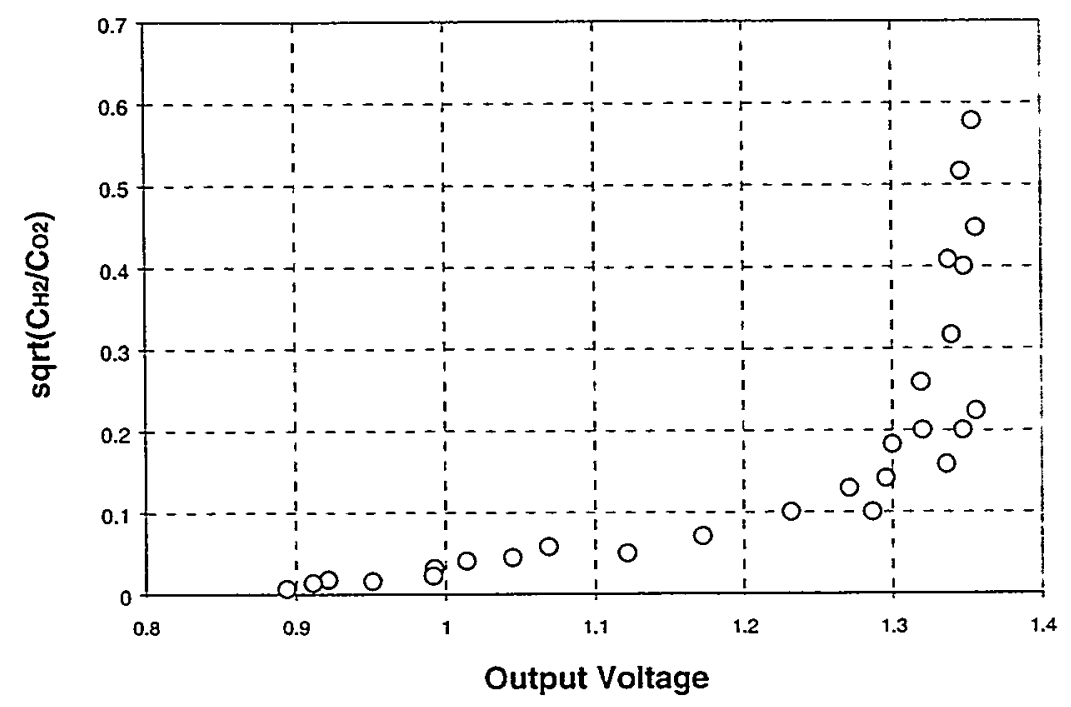

Figure 23. Response of Hydrogen FET 2541 for hydrogen in a nitrogen/oxygen atmosphere.

\section{Curve Fits}

It can be seen that the square root of the concentration ratio can be a useful means for accounting for the combined effect of hydrogen and oxygen on the FET response. Yet, the data has scatter above a sqrt(concentration ratio) of 0.1 .

After some trial and error with curve fits, it was found that a better relationship for describing the data was:

$$
\ln \left(\frac{\mathrm{C}_{\mathrm{H} 2}}{\mathrm{C}_{\mathrm{O} 2}^{1 / 3}}\right)=\mathrm{f}\left(\mathrm{V}_{\text {out }}\right)
$$

A plot of the data using this new ratio for FET 2541 is shown in Figure 24. The data for each oxygen concentration is shown as a different symbol. The data is more tightly clustered. Figure 25 shows the same data plotted with a logarithmic y axis. The data shows a distinct $\mathrm{S}$ curve that is typical of all of the data taken during calibration. A straight-line fit does a moderately good job of fitting the data, but the best fit is achieved using a $5^{\text {th }}$ order polynomial. See Figure 26. 


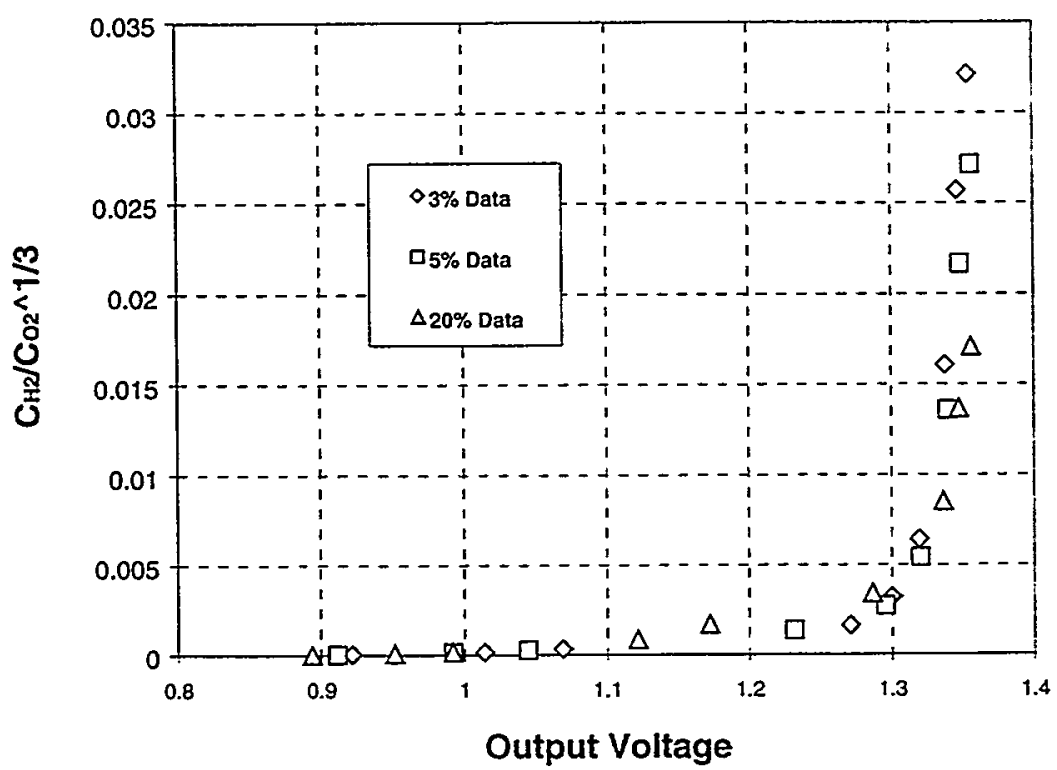

Figure 24. Response of Hydrogen FET 2541 to hydrogen concentrations in a nitrogen/oxygen atmosphere replotted using a new concentration ratio.

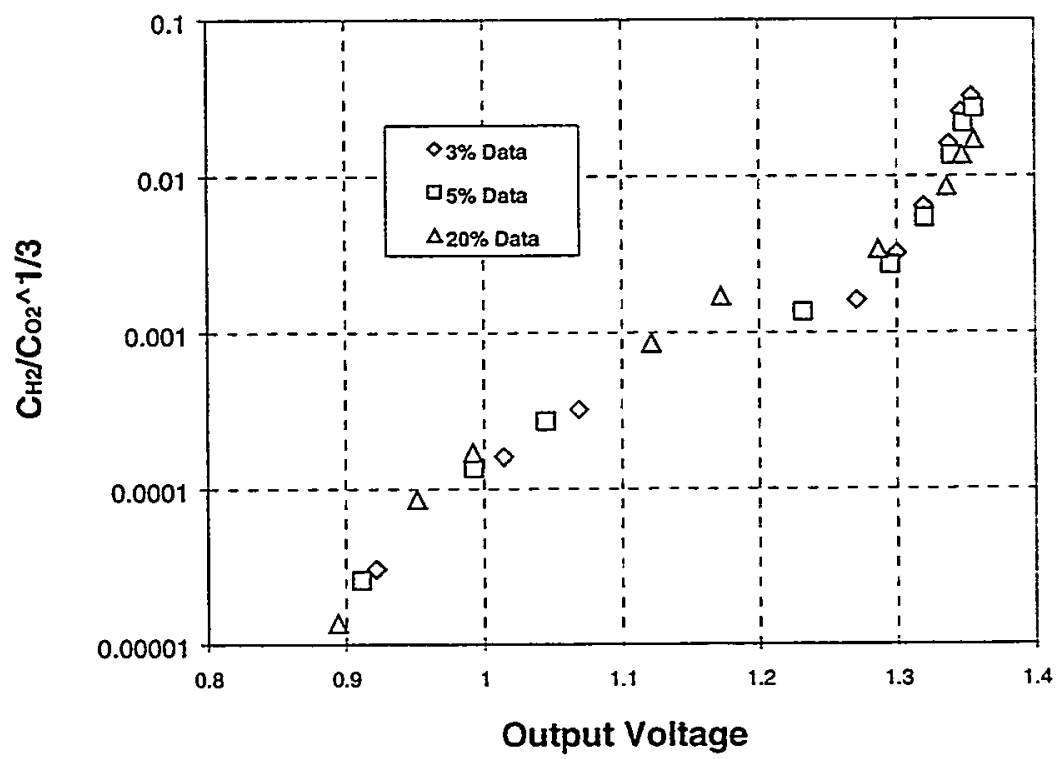

Figure 25. Figure 24 plotted with a logarithmic y axis. 


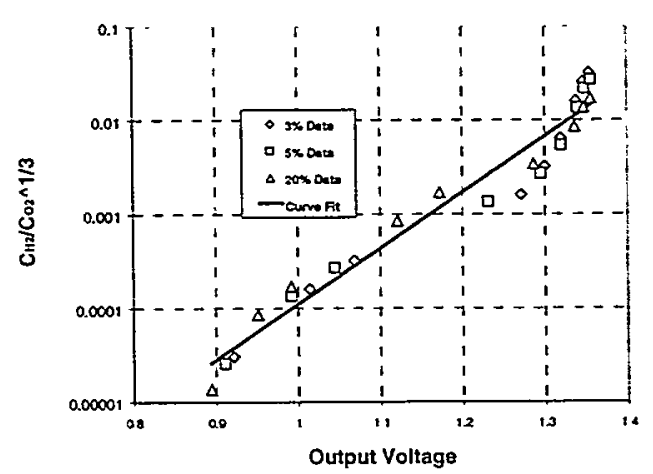

Straight Line Fit, $\mathrm{R}=0.9525$

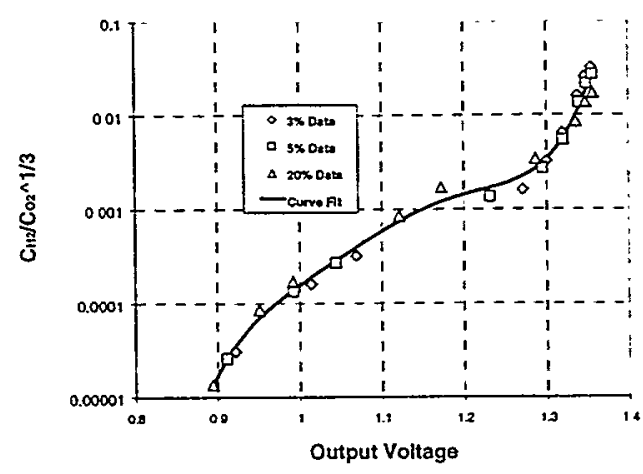

Polynomial Fit, $\mathrm{R}=0.9905$

Figure 26. Comparison of a straight-line and $5^{\text {th }}$ order polynomial fit.

The general form of the curve fits for the FET response data will take the following forms:

$$
\begin{array}{ll}
\ln \left(\frac{\mathrm{C}_{\mathrm{H} 2}}{\mathrm{C}_{\mathrm{O} 2}^{1 / 3}}\right)=\mathrm{a}_{0}+\mathrm{a}_{1} \mathrm{~V}+\mathrm{a}_{2} \mathrm{~V}^{2}+\mathrm{a}_{3} \mathrm{~V}^{3}+\mathrm{a}_{4} \mathrm{~V}^{4}+\mathrm{a}_{5} \mathrm{~V}^{5} & 3 \% \leq \mathrm{C}_{\mathrm{O} 2} \leq 20 \% \\
\ln \left(\sqrt{\mathrm{C}_{\mathrm{H} 2} \cdot \mathrm{p}_{\mathrm{amb}}}\right)=\mathrm{a}_{0}+\mathrm{a}_{1} \mathrm{~V}+\mathrm{a}_{2} \mathrm{~V}^{2}+\mathrm{a}_{3} \mathrm{~V}^{3} & \mathrm{C}_{\mathrm{O} 2}=0 \%
\end{array}
$$

where

$\mathrm{C}_{\mathrm{H} 2}=$ hydrogen concentration

$\mathrm{C}_{\mathrm{O} 2}=$ oxygen concentration

$\mathrm{V}=$ output voltage from hydrogen sensor board.

$\mathrm{p}_{\mathrm{amb}}=$ absolute ambient pressure, torr 
The coefficients for the equation for FETs 2536 and 2541 are shown in Table 7.

\begin{tabular}{ccccc}
\hline Table 7. Curve Fit Coefficients for FETs 2536 and 2541 \\
& FET2536 & FET2536 & FET2541 & FET2541 \\
& $0 \% \mathrm{O}_{2}$ & $3 \%$ to $20 \% \mathrm{O}_{2}$ & $0 \% \mathrm{O}_{2}$ & 3\% to $20 \% \mathrm{O}_{2}$ \\
\hline $\mathrm{a}_{0}$ & 555.920303 & -831.7510205 & 1980.628762 & -6700.067801 \\
$\mathrm{a}_{1}$ & -1452.466276 & 4549.54556 & -4619.140477 & 30617.21838 \\
$\mathrm{a}_{2}$ & 1243.926974 & -10052.46009 & 3565.768277 & -56001.10913 \\
$\mathrm{a}_{3}$ & -349.6783791 & 11050.6961 & -911.4436491 & 51132.75959 \\
$\mathrm{a}_{4}$ & 0 & -6024.157619 & 0 & -23288.86811 \\
$\mathrm{a}_{1}$ & 0 & 1301.58943 & 0 & 4231.305477 \\
$\mathrm{R}$ & 0.9990 & 0.9910 & 0.9990 & 0.9905 \\
\hline
\end{tabular}




\section{Performance}

\section{Repeatability and Accuracy}

Each time that the FETs were heated, the unheated reading shifted. Tables 8 and 9 illustrate what was observed. The sequence of calibration runs occurred as listed below:

$\begin{array}{ll}\text { October 15, 1998 } & \text { FET heaters off } \\ \text { October 16, 1998 } & \text { FET heaters on } \\ \text { October 18, 1998 } & \text { FET heaters off } \\ \text { October 21, 1998 } & \text { FET heaters off }\end{array}$

When a heated calibration occurred between 2 unheated calibrations, the FETs showed a shift in their response. Table 8 shows that FET 2536 had a.4\% to $5 \%$ shift and FET 2541 had a noticeable shift at sub 1000 ppm levels, but not much effect above 1000 ppm. Table 9 shows the results when 2 calibration runs at room temperature (heaters off) were performed consecutively without an intervening heated calibration. Both FETs show a variation of only $1 \%$ to $2 \%$ over most of the calibration range.

Heating may have a stabilizing effect on FET performance variation. FET 2541 had been cycled from $90 \mathrm{C}$ to room temperature several times in earlier testing, but FET 2536 was first heated on October 16 . This indicates that it is possible that the FETs vary upon heating and cooling initially and eventually 'break-in' after enough temperature cycles and are no longer affected by temperature cycles. Unfortunately, we did not have the time to continue cycling the FETs to determine their long-term behavior. Lacking better information, it seems that maintaining the FETs at a constant temperature will result in more consistent, repeatable measurements.

A high temperature anneal at $250 \mathrm{C}$ in a $2 \%$ hydrogen/98\% nitrogen atmosphere results in more consistent FET behavior [Hughes, 1998]. We had initially planned to use annealed FETs, but the first batch of FETs that were annealed had a very high failure rate. Therefore, rather than destroy most of our stock of FETs in the annealing process, we used un-annealed FETs in the Add-On boards. It is possible that the temperature cycling during calibration may be having a similar, though slower and less destructive, effect as the annealing process.

Lastly, if a constant operating temperature is desired, it is difficult to calibrate at $90 \mathrm{C}$, and then install the FET into an instrumentation package, which is then installed into a test device, without turning power off to the FET, and having it return to room temperature. Therefore, it seems that a room temperature calibration and application of the FETs is preferred for consistent, repeatable measurements. 


\section{Table 8. Comparison of unheated calibration results when the FETs}

were heated in between.

\begin{tabular}{|c|c|c|c|c|}
\hline & \multicolumn{4}{|c|}{2536 at $0 \%$ O2 - Unheated } \\
\hline & 15-Oct & $18-$ Oct & Delta & $\%$ Change \\
\hline 9.5 & 1.0117 & 1.1930 & 0.1814 & 17.93 \\
\hline 50 & 1.2008 & 1.2461 & 0.0453 & 3.77 \\
\hline 100 & 1.2244 & 1.2647 & 0.0403 & 3.29 \\
\hline 500 & 1.2574 & 1.3012 & 0.0438 & 3.48 \\
\hline 1000 & 1.2716 & 1.3176 & 0.0460 & 3.62 \\
\hline 2000 & 1.2848 & 1.3336 & 0.0489 & 3.80 \\
\hline 5000 & 1.3016 & 1.3544 & 0.0528 & 4.06 \\
\hline 8000 & 1.3105 & 1.3657 & 0.0552 & 4.21 \\
\hline 10000 & 1.3142 & 1.3701 & 0.0559 & 4.25 \\
\hline & & 6 at $3 \%$ & 2. Unhea & \\
\hline & 15-Oct & $18-\mathrm{Oct}$ & Delta & $\%$ Change \\
\hline 9.5 & 0.7392 & 0.7839 & 0.0447 & 6.05 \\
\hline 50 & 0.8401 & 0.8921 & 0.0520 & 6.18 \\
\hline 100 & 0.8955 & 0.9467 & 0.0511 & 5.71 \\
\hline 500 & 1.0562 & 1.1056 & 0.0494 & 4.68 \\
\hline 1000 & 1.1440 & 1.2230 & 0.0790 & 6.90 \\
\hline 2000 & 1.2555 & 1.3276 & 0.0722 & 5.75 \\
\hline 5000 & 1.2953 & 1.3570 & 0.0617 & 4.77 \\
\hline 8000 & 1.3073 & 1.3692 & 0.0619 & 4.73 \\
\hline 10000 & 1.3117 & 1.3740 & 0.0624 & 4.76 \\
\hline & & 36 at $5 \%$ & 2-Unhea & \\
\hline & $15-$ Oct & $18-\mathrm{Oct}$ & Delta & $\%$ Change \\
\hline 9.5 & 0.7261 & 0.7740 & 0.0479 & 6.59 \\
\hline 50 & 0.8180 & 0.8730 & 0.0550 & 6.72 \\
\hline 100 & 0.8804 & 0.9261 & 0.0456 & 5.18 \\
\hline 500 & 1.0241 & 1.0806 & 0.0565 & 5.52 \\
\hline 1000 & 1.1131 & 1.1741 & 0.0611 & 5.49 \\
\hline 2000 & 1.2295 & 1.3240 & 0.0945 & 7.68 \\
\hline 5000 & 1.2939 & 1.3581 & 0.0642 & 4.96 \\
\hline 8000 & 1.3070 & 1.3708 & 0.0638 & 4.88 \\
\hline 10000 & 1.3117 & 1.3757 & 0.0640 & 4.88 \\
\hline
\end{tabular}

\begin{tabular}{rcccc}
\multicolumn{5}{c}{2541 at 0\% } \\
\multicolumn{1}{c}{ O2 - Unheated } \\
& $15-$ Oct & $18-$ Oct & Delta & \% Change \\
\cline { 2 - 5 } 9.5 & 0.9808 & 1.2643 & 0.2835 & 28.90 \\
50 & 1.3024 & 1.3194 & 0.0170 & 1.30 \\
100 & 1.3327 & 1.3380 & 0.0053 & 0.40 \\
500 & 1.3652 & 1.3750 & 0.0098 & 0.72 \\
1000 & 1.3856 & 1.3915 & 0.0058 & 0.42 \\
2000 & 1.4025 & 1.4075 & 0.0050 & 0.35 \\
5000 & 1.4205 & 1.4282 & 0.0077 & 0.54 \\
8000 & 1.4289 & 1.4395 & 0.0105 & 0.74 \\
10000 & 1.4332 & 1.4440 & 0.0109 & 0.76 \\
\hline
\end{tabular}

\begin{tabular}{|c|c|c|c|c|}
\hline & \multicolumn{4}{|c|}{2541 at 3\% O2 - Unheated } \\
\hline & 15-Oct & $18-O c t$ & Delta & $\%$ Change \\
\hline 9.5 & 0.8510 & 0.8749 & 0.0239 & 2.81 \\
\hline 50 & 0.9675 & 1.0043 & 0.0368 & 3.80 \\
\hline 100 & 1.0201 & 1.0617 & 0.0415 & 4.07 \\
\hline 500 & 1.1782 & 1.2402 & 0.0619 & 5.26 \\
\hline 1000 & 1.3051 & 1.3711 & 0.0660 & 5.06 \\
\hline 2000 & 1.3881 & 1.4050 & 0.0170 & 1.22 \\
\hline 5000 & 1.4133 & 1.4314 & 0.0181 & 1.28 \\
\hline 8000 & 1.4245 & 1.4432 & 0.0187 & 1.32 \\
\hline 10000 & 1.4292 & 1.4479 & 0.0188 & 1.31 \\
\hline
\end{tabular}

\begin{tabular}{rcccc}
\multicolumn{5}{c}{2541 at $5 \%$ O2 - Unheated } \\
& $15-$ Oct & $18-$ Oct & Delta & \% Change \\
\cline { 2 - 5 } 9.5 & 0.8470 & 0.8628 & 0.0158 & 1.87 \\
50 & 0.9453 & 0.9829 & 0.0376 & 3.98 \\
100 & 1.0126 & 1.0385 & 0.0260 & 2.56 \\
500 & 1.1542 & 1.2091 & 0.0549 & 4.76 \\
1000 & 1.2447 & 1.3514 & 0.1066 & 8.57 \\
2000 & 1.3826 & 1.4053 & 0.0227 & 1.64 \\
5000 & 1.4167 & 1.4337 & 0.0170 & 1.20 \\
8000 & 1.4264 & 1.4458 & 0.0194 & 1.36 \\
10000 & 1.4309 & 1.4506 & 0.0197 & 1.38 \\
\hline
\end{tabular}

The FETS were heated for a calibration run on October 16, 1998. 
Table 9. Comparison of unheated calibration results when the FETs were not heated in between.

\begin{tabular}{rcccc}
\multicolumn{5}{c}{2536 at 0\% O2 - Unheated } \\
\cline { 2 - 5 } 9.5 & $18-$ Oct & $21-$ Oct & Delta & $\%$ Change \\
50 & 1.2460 & 1.1769 & -0.0161 & -1.35 \\
100 & 1.2647 & 1.2784 & 0.0324 & 2.60 \\
500 & 1.3012 & 1.3374 & 0.0373 & 2.95 \\
1000 & 1.3176 & 1.3528 & 0.0363 & 2.79 \\
2000 & 1.3336 & 1.3676 & 0.0340 & 2.67 \\
5000 & 1.3544 & 1.3869 & 0.0325 & 2.55 \\
8000 & 1.3657 & 1.3969 & 0.0312 & 2.40 \\
10000 & 1.3701 & 1.4011 & 0.0310 & 2.26 \\
\hline
\end{tabular}

\begin{tabular}{rcccc} 
& \multicolumn{5}{c}{2541 at 0\% O2 - Unheated } \\
\cline { 2 - 5 } 9.5 & $18-$ Oct & $21-$ Oct & Delta & $\%$ Change \\
50 & 1.31943 & 1.2037 & -0.0606 & -4.79 \\
100 & 1.3380 & 1.3399 & 0.0205 & 1.55 \\
500 & 1.3750 & 1.3656 & 0.0276 & 2.07 \\
1000 & 1.3915 & 1.4182 & 0.0268 & 1.92 \\
2000 & 1.4075 & 1.4338 & 0.0263 & 1.87 \\
5000 & 1.4282 & 1.4535 & 0.0254 & 1.77 \\
8000 & 1.4395 & 1.4641 & 0.0246 & 1.71 \\
10000 & 1.4440 & 1.4682 & 0.0242 & 1.68 \\
\hline
\end{tabular}

\begin{tabular}{rcccc} 
& \multicolumn{5}{c}{ 2536 at 3\% O2 - Unheated } \\
\cline { 2 - 5 } & $18-$ Oct & $21-$ Oct & Delta & $\%$ Change \\
9.5 & 0.7839 & 0.8285 & 0.0446 & 5.69 \\
50 & 0.8921 & 0.9134 & 0.0213 & 2.39 \\
100 & 0.9467 & 0.9667 & 0.0200 & 2.12 \\
500 & 1.1056 & 1.1094 & 0.0038 & 0.34 \\
1000 & 1.2230 & 1.2017 & -0.0213 & -1.74 \\
2000 & 1.3276 & 1.3532 & 0.0256 & 1.93 \\
5000 & 1.3570 & 1.3847 & 0.0277 & 2.04 \\
8000 & 1.3692 & 1.3967 & 0.0276 & 2.02 \\
10000 & 1.3740 & 1.4015 & 0.0274 & 2.00 \\
\hline
\end{tabular}

\begin{tabular}{rcccc} 
& \multicolumn{5}{c}{ 2541 at 3\% } & O2 - Unheated \\
\cline { 2 - 5 } & $18-$ Oct & $21-$ Oct & Delta & \% Change \\
9.5 & 0.8749 & 0.8933 & 0.0184 & 2.10 \\
50 & 1.0043 & 1.0032 & -0.0011 & -0.10 \\
100 & 1.0617 & 1.0626 & 0.0009 & 0.08 \\
500 & 1.2402 & 1.2315 & -0.0087 & -0.70 \\
1000 & 1.3711 & 1.3823 & 0.0112 & 0.81 \\
2000 & 1.4050 & 1.4249 & 0.0199 & 1.41 \\
5000 & 1.4314 & 1.4520 & 0.0206 & 1.44 \\
8000 & 1.4432 & 1.4637 & 0.0205 & 1.42 \\
10000 & 1.4479 & 1.4686 & 0.0207 & 1.43 \\
\hline
\end{tabular}

\begin{tabular}{|c|c|c|c|c|}
\hline & & ats & -010 & \\
\hline & $18-O c t$ & 21-Oct & Delta & $\%$ Change \\
\hline 9.5 & 0.7740 & 0.8210 & 0.0470 & 6.08 \\
\hline 50 & 0.8730 & 0.8998 & 0.0268 & 3.07 \\
\hline 100 & 0.9261 & 0.9504 & 0.0243 & 2.62 \\
\hline 500 & 1.0806 & 1.0887 & 0.0080 & 0.74 \\
\hline 1000 & 1.1741 & 1.1711 & -0.0030 & -0.26 \\
\hline 2000 & 1.3240 & 1.3466 & 0.0227 & 1.71 \\
\hline 5000 & 1.3581 & 1.3854 & 0.0272 & 2.01 \\
\hline 8000 & 1.3708 & 1.3979 & 0.0271 & 1.97 \\
\hline 10000 & 1.3757 & 1.4026 & 0.0269 & 1.95 \\
\hline
\end{tabular}

\begin{tabular}{rcccc} 
& \multicolumn{5}{c}{ 2541 at 5\% 02 - Unheated } \\
\cline { 2 - 5 } 9.5 & $18-$ Oct & $21-$ Oct & Delta & $\%$ Change \\
50 & 0.9829 & 0.8856 & 0.0227 & 2.64 \\
100 & 1.0385 & 0.9867 & 0.0037 & 0.38 \\
500 & 1.2091 & 1.20754 & 0.0069 & 0.67 \\
1000 & 1.3514 & 1.3191 & -0.0016 & -0.13 \\
2000 & 1.4053 & 1.4238 & 0.0185 & -2.39 \\
5000 & 1.4337 & 1.4538 & 0.0200 & 1.32 \\
8000 & 1.4458 & 1.4659 & 0.0201 & 1.39 \\
10000 & 1.4506 & 1.4704 & 0.0198 & 1.37 \\
\hline
\end{tabular}




\section{Variation Between Parts}

Supposedly identical FETs show considerable variation in threshold voltages. As a result, it is not possible simply to take out a failed FET, and replace it with a new FET, without recalibrating and adjusting the signal conditioning zero and span.

For example, Table 10 lists the FET voltages that would have to be signal conditioned for the 2 FETs used in the Add-On boards. It can be seen that the span does not vary too much from FET to FET, but the zero does.

Suppose the signal conditioning was adjusted to convert the FET 2536 output to the 0.4 to 1.4 volts required by the analog to digital converter. If FET 2536 failed, and was replaced by FET 2541 without rezeroing the signal conditioning, the board output in a $0 \%$ oxygen atmosphere would indicate that the hydrogen concentration was always below $10 \mathrm{ppm}$ when in reality it was varying between 10 and 10,000 ppm. At 20\% oxygen, the two ranges would overlap some, but the readings would be considerably off.

\section{Table 10. FET Threshold Voltages}

FET 2536

FET 2541

\begin{tabular}{lllllll} 
& $10 \mathrm{ppm}$ & $10,000 \mathrm{ppm}$ & Span & $10 \mathrm{ppm}$ & $10,000 \mathrm{ppm}$ & Span \\
\cline { 2 - 7 } $0 \%$ Oxygen & $2.65 \mathrm{~V}$ & $2.59 \mathrm{~V}$ & $0.06 \mathrm{~V}$ & $2.70 \mathrm{~V}$ & $2.64 \mathrm{~V}$ & $0.06 \mathrm{~V}$ \\
$20 \%$ Oxygen & $2.83 \mathrm{~V}$ & $2.59 \mathrm{~V}$ & $0.24 \mathrm{~V}$ & $2.90 \mathrm{~V}$ & $2.64 \mathrm{~V}$ & $0.26 \mathrm{~V}$
\end{tabular}

Note: Both FETs are driven by a constant current source of 100 micro-amps 


\section{Temperature Sensitivity}

The design of the Hydrogen Sensor Board included features to minimize the sensitivity to temperature. However, the Hydrogen Sensor Board output was still sensitive to temperature. In order to compensate for temperature influences, the Hydrogen Sensor Board was operated in an oven capable of providing an accurate and constant temperature. The Hydrogen Sensor Board was held at 30, 50, 70, 90, and $130^{\circ} \mathrm{F}$ for an hour each. The Hydrogen Sensor Board output was monitored by a small telemetry package as shown in Figure 27 and radioed to a receiver. The Hydrogen Sensor Board output was converted to 0 to 256 counts by the telemetry package. The data is shown plotted in Figure 28.

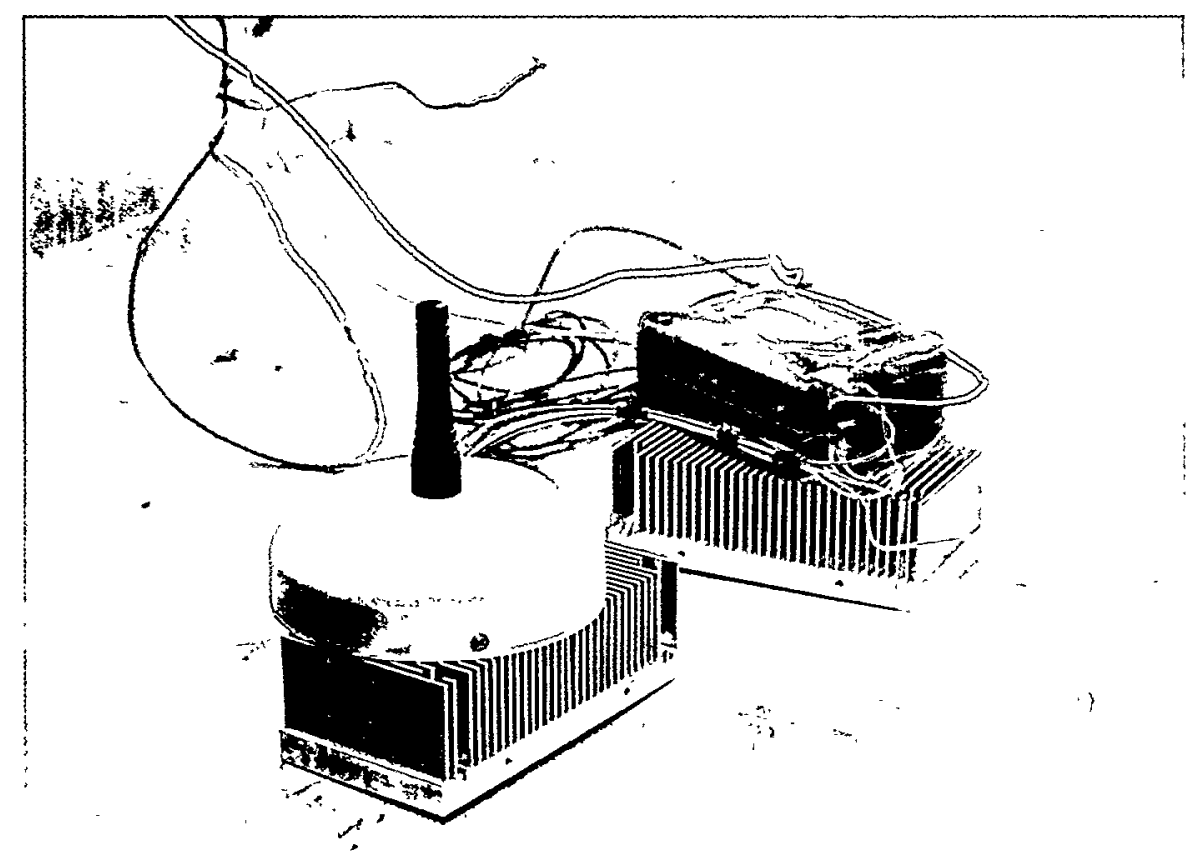

$\sin 2 \sin 7$

Figure 27. Temperature Sensitivity Testing of the Hydrogen Sensor Boards 


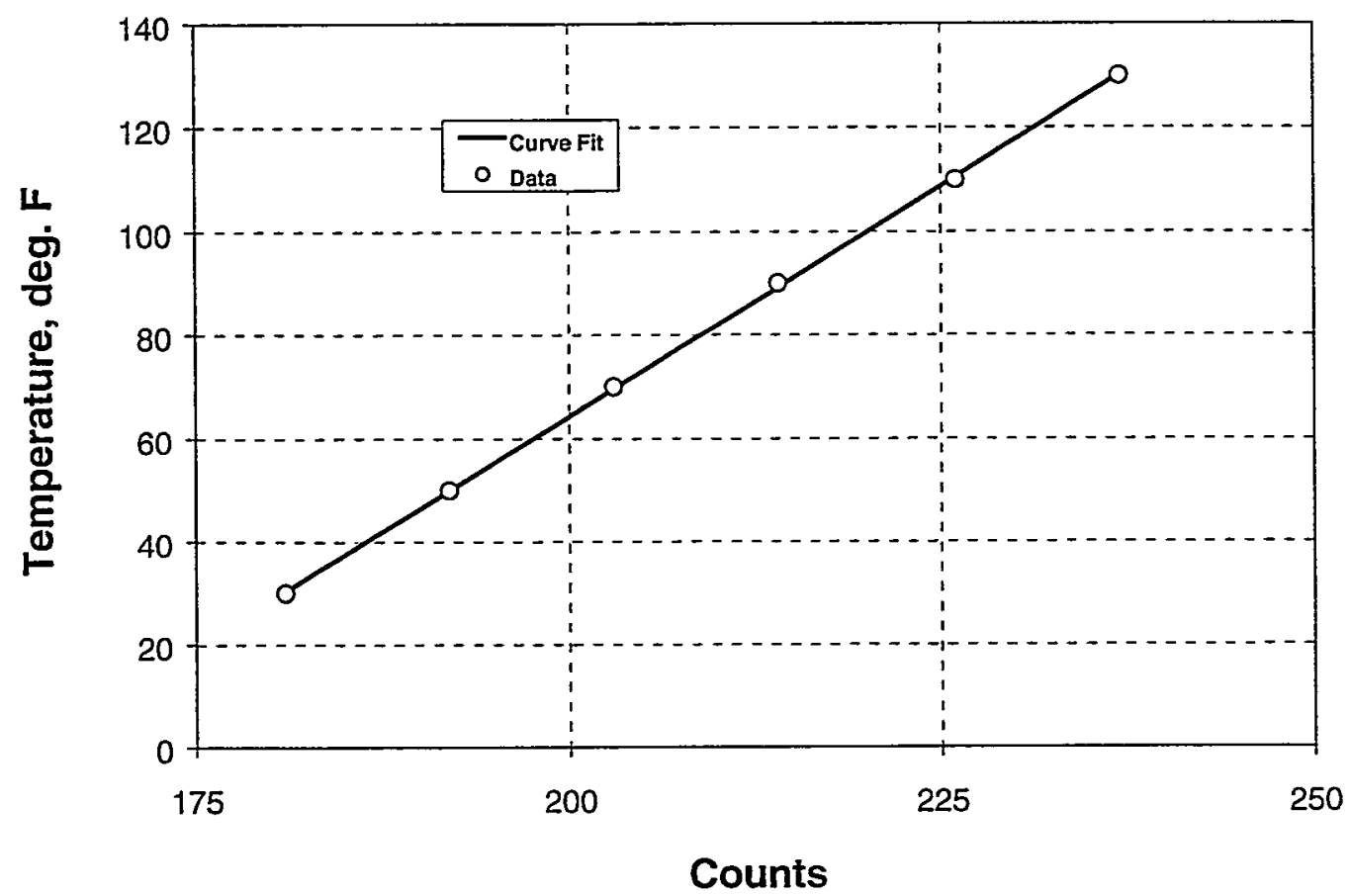

Figure 28. Effect of Temperature on the Hydrogen Sensor Board Output.

The effect of temperature variations on output is nearly linear and can be described by the equation:

$\mathrm{T}=1.7808 \mathrm{Cnt}-291.8971$

where

$\mathrm{T}=$ temperature, deg. $\mathrm{F}$

Cnt $=$ Hydrogen Sensor Board output in counts

Counts are related to volts by the following equation:

$\mathrm{V}=\frac{\mathrm{Cnt}}{255}+0.4$

where

$\mathrm{V}=$ Hydrogen Sensor Board output in volts

Cnt $=$ Hydrogen Sensor Board output in counts 
Overall, the Hydrogen Sensor Board sensitivity to temperature was $2.2 \mathrm{mV}$ per degree Fahrenheit. In Table 10, the typical span of the hydrogen FET output from 10 to $10,000 \mathrm{ppm}$ of hydrogen concentration in a non-oxygen atmosphere is about $60 \mathrm{mV}$. After amplification by the signal conditioning, the change in Hydrogen Sensor Board output over a 10 to $10,000 \mathrm{ppm}$ hydrogen concentration variation is $252 \mathrm{mV}$. The total range of hydrogen measurement is equivalent to about a $110^{\circ} \mathrm{F}$ change in temperature. Therefore, temperature can have a very large influence on the hydrogen reading and must be compensated for during data processing.

\section{Response Time}

Concerns were voiced regarding sluggish response or non-response of the unheated FET to changes in hydrogen concentration. Therefore, it was decided to create the hydrogen sensor board incorporating options for operating the FET heaters as well as signal conditioning for the FET output.

Heating of the Robust Hydrogen Sensor serves to improve the response time of the hydrogen FET to a change in hydrogen concentration, particularly a decreasing hydrogen concentration. The actual effect in response time due to heating the hydrogen sensors was evaluated during the calibration testing.

Figure 29 shows the maximum rate of response for a series of step changes in hydrogen concentration over a range of constant oxygen concentrations. In no case is the rate of response of the heated hydrogen FET considerably different from an unheated hydrogen FET.

Since the hydrogen FETs were tested in a chamber about 0.125 cubic feet in volume, the free volume of the chamber may largely control the rate of response. However, the intended application is to have the hydrogen FET enclosed in a volume to monitor slow changes in hydrogen concentration over long periods of time. So the test setup should give a reasonable relative value between heating and not heating the hydrogen FET.

Based on the observed responses, it was decided that there was no value in heating the hydrogen FETs intermittently or continuously. 

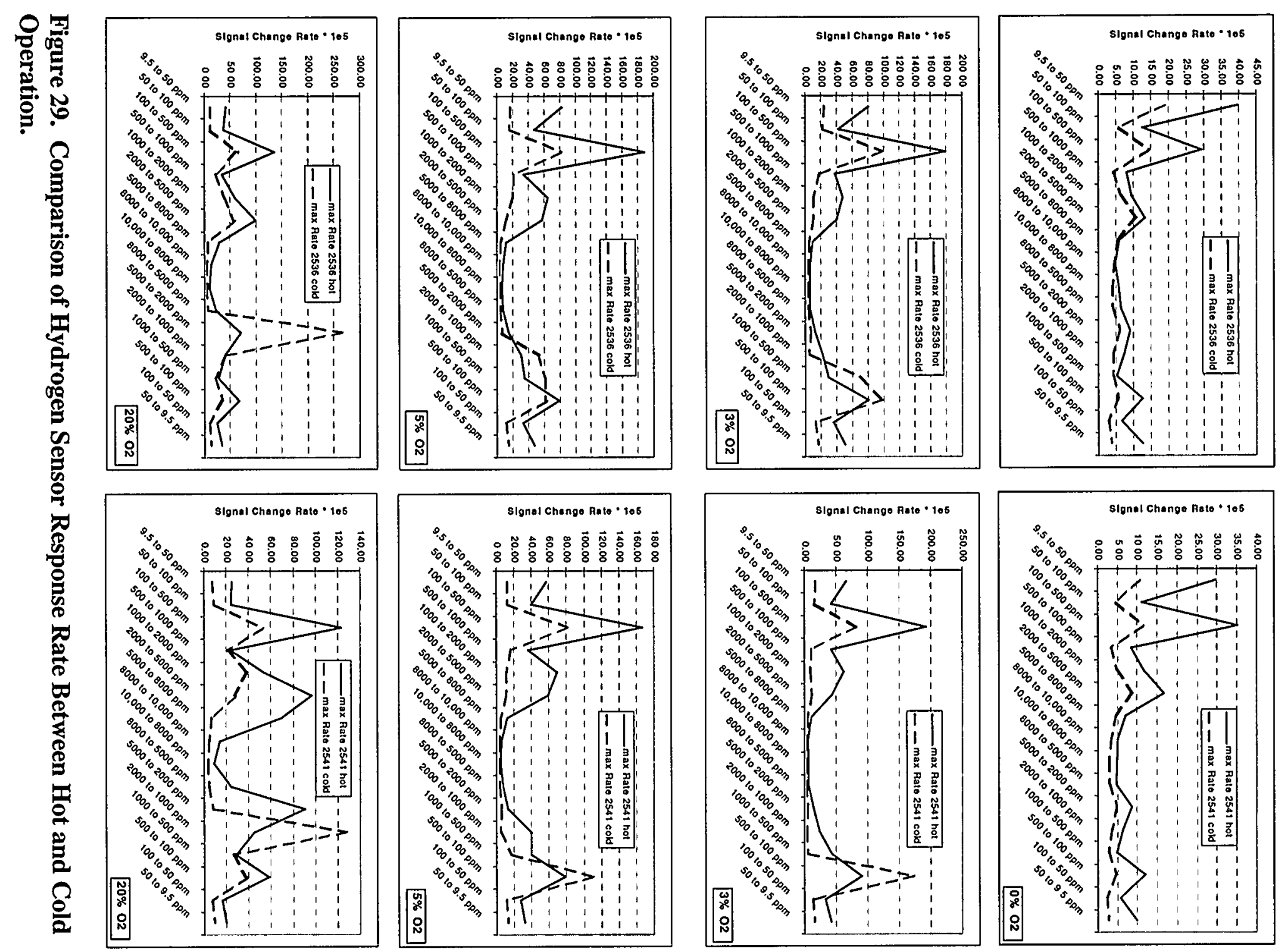


\section{Conclusions and Recommendations}

A low-power signal conditioning and heater control board was fabricated for the Sandia Robust Hydrogen Sensor. It has been found that:

1. Power consumption of the FET excitation and signal conditioning circuitry was $<200 \mathrm{uA}$ (excluding $1.3 \mathrm{~mA}$ for the timer optoisolator).

2. The response of the hydrogen FET to hydrogen is noticeably different when oxygen is and is not present.

3. When in the presence of oxygen, a single calibration curve can be developed to determine the hydrogen concentration if the hydrogen FET threshold voltage and oxygen concentration is known.

4. Some hydrogen FETs show marked shifts in their performance after they have been heated and then cooled. It is recommended that the hydrogen FETs be operated unheated.

5. The response of the hydrogen FETs tested to a step change in hydrogen level is not significantly different between heated and unheated operation when the sensors are in an enclosure with free volume. It is recommended that the hydrogen FETs be operated unheated to reduce power consumption.

6. The hydrogen FETs tested had the same threshold voltage change over a 10 ppm to $10,000 \mathrm{ppm}$ hydrogen concentration range. However, the absolute voltage ranges were quite different. Until hydrogen FETs become much more uniform in their response, each hydrogen FET will have to be calibrated prior to service. A standard calibration curve is not possible.

7. The hydrogen FET output, along with the signal conditioning, is noticeably sensitive to temperature. The hydrogen FET and its signal conditioning must be characterized for temperature response so this may be eliminated during data processing. 


\section{References}

1. B. M. Mickelsen, G. R. Laguna, and M. R. Daily, "Integrated Nuclear Material Monitor", Proceedings of the $38^{\text {th }}$ Annual Meeting of the Institute of Nuclear Materials Management, July 1997.

2. R.C. Hughes, D.J. Moreno, M.W. Jenkins, and J.L. Rodriguez,'The Response of the Sandia Robust Wide Range Hydrogen Sensor to $\mathrm{H}_{2}-\mathrm{O}_{2}$ Mixtures", 1994 SolidState Sensor and Actuator Workshop, June 13-16, Hilton Head Island, SC.

3. I. Lundstöm, "Hydrogen Sensitive MOS-Structures Part 1: Principles and Applications", Sensors and Actuators, I, 403, (1981).

4. Personal communication with M. Jenkins and Larry Anderson, Microsensor R\&D Department, 1999.

5. Personal communication with Bob Hughes, Microsensor R\&D Department, Sandia National Laboratory, 1998. 
This page left blank on purpose. 


\section{APPENDIX A - Initial Specifications}

\section{General:}

The INUMM ESP contains the power source, power switching circuitry, multiplexer, A/D converter, and RF communications for operating the $\mathrm{H}_{2} \mathrm{FET}$ and reporting its output value. The ESP power source is inadequate to run the power FETs on the $\mathrm{H}_{2}$ sensor chip which serve as heaters to clean up the $\mathrm{H}_{2} \mathrm{FET}$ by driving the hydrogen out of its junction. Therefore, the power FET heaters will be powered by a power supply external to the AF\&F.

A separate add-on board containing circuitry for signal conditioning the $\mathrm{H}_{2}$ FET output and for controlling the power FET heaters is required. The add-on board may have to perform power conditioning in order to correctly power the $\mathrm{H}_{2} \mathrm{FET}$.

\section{Statement of Work:}

1. All parts and labor to be supplied or procured by Department 1738 .

2. Select 4 functional hydrogen sensors.

3. Design $\mathrm{H}_{2}$ FET power supply/signal conditioning circuit. The $\mathrm{H}_{2} \mathrm{FET}$ and its signal conditioning are to be powered by the battery in the ESP. Power supplied by the ESP to the add-on board is 3.6 volts (direct battery voltage) and is limited to a maximum current draw of $3 \mathrm{~mA}$. The $3 \mathrm{~mA}$ current is broken down as follows:

$2 \mathrm{~mA}$ for the $\mathrm{H}_{2} \mathrm{FET}$ and signal conditioning

$1 \mathrm{~mA}$ for the heater control

An alternative voltage for powering only the $\mathrm{H}_{2} \mathrm{FET}$ is 7.2 volts supplied by a voltage doubling circuit. If 7.2 volts is required to power the $\mathrm{H}_{2} \mathrm{FET}$, it is preferred that the voltage doubling circuit be part of the add-on board rather than using the voltage doubling circuit of the ESP.

Coordinate with Larry Sheets, AS/FM\&T, and Scott Kuszmaul, SNL/NM, on where to tap into the ESP circuits. Nominal wiring is per Figure 10. 
Scale the $\mathrm{H}_{2}$ FET output to match A/D input range as follows:

$$
\begin{aligned}
& 0.4 \mathrm{~V}=0 \mathrm{ppm} \mathrm{H} \mathrm{H}_{2} \text { concentration } \\
& 1.4 \mathrm{~V}=5000 \mathrm{ppm} \mathrm{H}_{2} \text { concentration }
\end{aligned}
$$

Please verify A/D input range with Scott Kuszmaul, 2338.

Noise on the output signal caused by the signal conditioning should be less than $2 \mathrm{mV}$. Noise level will be measured during testing.

Provide 12-inch long 24 gauge Teflon coated stranded wire connections per interface drawing in Figure 10.

4. Design a heater control circuit to provide closed-loop control which, when powered by externally supplied $3.6 \mathrm{~V}( \pm 0.5 \mathrm{~V})$ and the FET Power line is at OV $( \pm 0.5 \mathrm{~V})$, will maintain the $\mathrm{H}_{2} \mathrm{FET}$ temperature at 180 degrees centigrade for 15 minutes, and then switch off the heater power.

The heater will remain off until the FET Power line goes to $3.6 \mathrm{~V}( \pm 0.5 \mathrm{~V})$, resetting the heater control circuit, which then switches on the heater power when the FET Power line goes to $0 \mathrm{~V}( \pm 0.5 \mathrm{~V})$. The event/time sequence for the heat operation is shown below:

Consult with Bob Hughes, 1315 , to verify the heater on time that will clean the $\mathrm{H}_{2} \mathrm{FET}$ and ready it for the next sample, the heater temperature set point, and for other details regarding the hydrogen sensor.

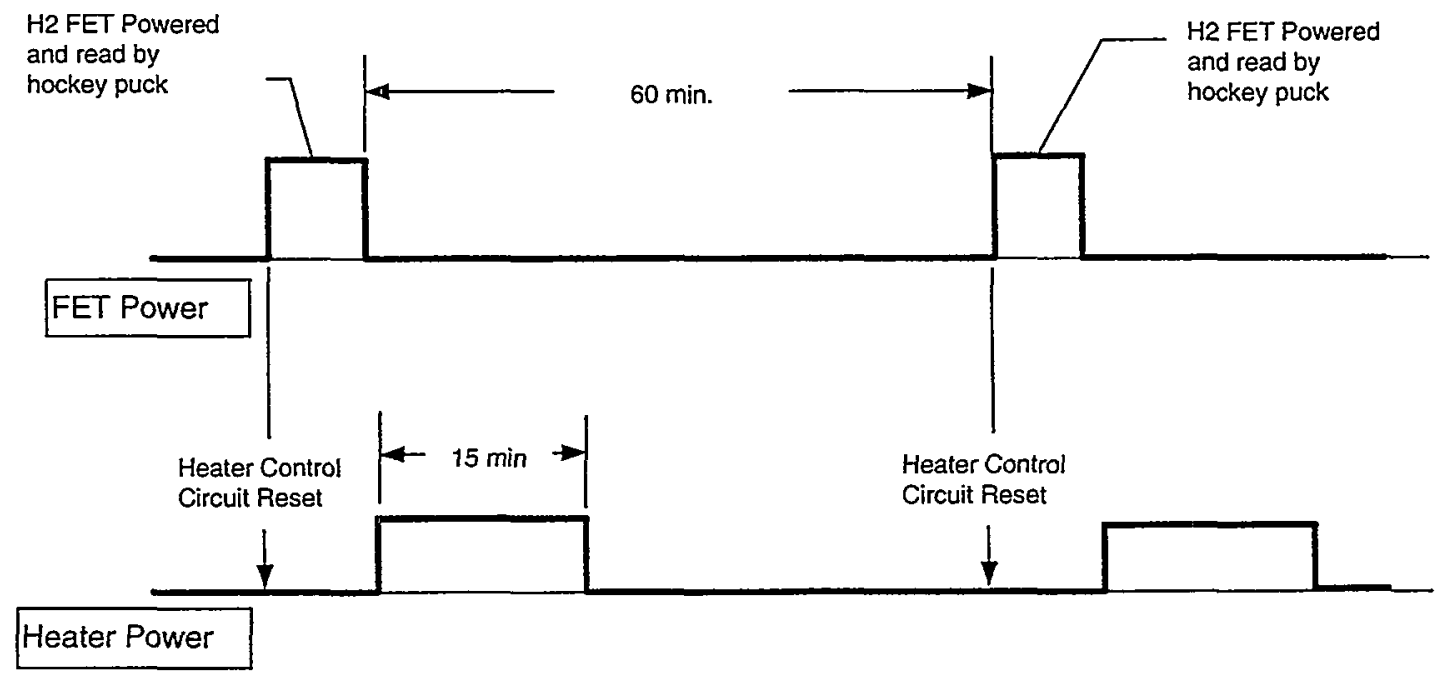

Figure A-1. Power FET Heater Power Control Sequence 
The heater control circuit cannot draw more than $1 \mathrm{~mA}$ from the $\mathrm{H}_{2}$ FET Power line.

The heater circuit shall have a mechanical switch, which, when activated, will bypass the heater timing control described above, and continuously power the heaters via the temperature feedback loop.

Consult with Scott Kuszmaul, 2338, as required to define interfaces with the current production ESP, functioning of the ESP, and to obtain sample schematics for $\mathrm{H}_{2}$ FET circuits.

Modifications to any ESPs will be performed by AS/FM\&T.

Provide 12-inch long, 24 gauge Teflon coated stranded wire connections for the heater external power per interface drawing in Figure 10.

5. Build 4 circuit boards containing these circuits. Boards with components loaded and protective enclosure installed must fit in a volume $0.5^{\text {" high }}$ and having a form which fits within the boundaries defined by Figure 11. The protective enclosure need only protect against accidental electrical contact with the add-on board, and damage to parts due to normal handling.

6. Load components on 2 circuit boards. Test to verify operation of FET signal conditioning and heater control circuit. The remaining 2 circuit boards are reserve.

7. Support calibration of $2 \mathrm{H}_{2}$ Sensor Add-On boards.

Deliverables:

1. 2 assembled Hydrogen Sensor Add-On boards with protective packaging, tested and ready for calibration on September 1, 1998.

2. Testing support for Hydrogen Sensor Add-On board calibration and rework support to fix or alter boards to function correctly if problems are found during calibration. 
3. The following items delivered to Scott Faas on or before September 30, 1998:

a. 2 bare Hydrogen Sensor Add-On boards.

b. 2 tested hydrogen sensors, or the remaining hydrogen sensors of the 4 that were tested and verified functional in Statement of Work, task 1.

c. B size drawings of Hydrogen Sensor Add-On board layout and circuit diagram.

d. Data files of the Hydrogen Sensor Add-On board layout and circuit diagram. Format of delivery media TBD.

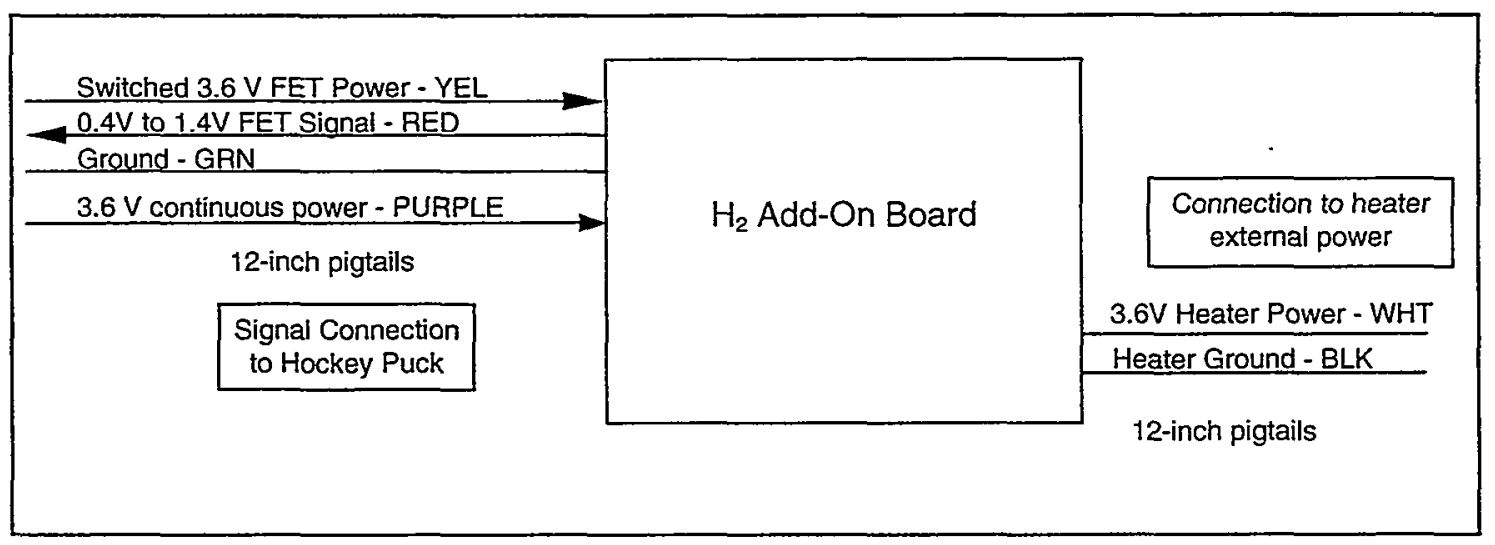

Figure A-2. Hydrogen Sensor Add-On Board Interfaces 


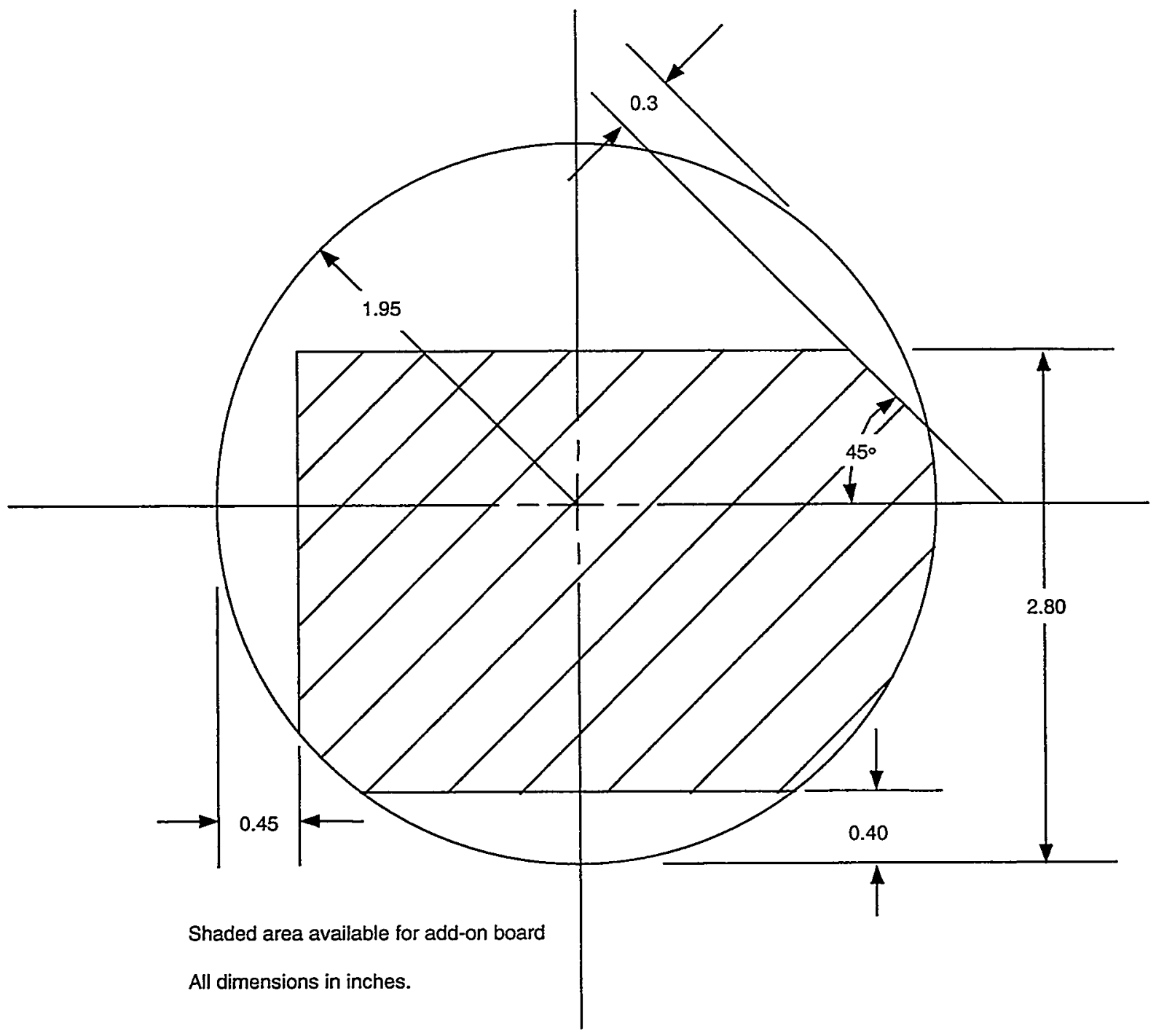

Figure A-3. Maximum Area Allocated for Add-On Board. 
This page left blank on purpose. 


\section{Appendix B \\ Version 2 Hydrogen FET Bias Circuit}

Figure B-1 shows the schematic of the hydrogen FET and the opamp current regulator. In this design the opamp monitors the current through the hydrogen FET via the current sensing resistor R41. In this design setting the current is easy - simply adjust the reference voltage going to the positive leg of the opamp (R43). Not only is current adjustment easy but the temperature coefficient of this source is near the best temperature coefficient obtainable from the LM134. This is because the current depends only on the temperature coefficient of the resistor (which can be 10ppm) and the temperature coefficient of the reference voltage (3-10ppm). Together these two temperature coefficient values yield a total temperature coefficient comparable to the LM134 at its best. Alas, the circuit has one drawback; the voltage developed across the current sense resistor gets added to the threshold voltage, $\mathrm{V}_{\text {th }}$, of the hydrogen FET which makes the overall circuit somewhat harder to setup since you have a constant offset to deal with. This is not really a problem, it just means you need to think in terms of $\mathrm{V}_{\text {th }}+$ offset instead of $V_{t h}$. If you view the output from this first opamp (U3-1) you will need to remember that the offset is present.

Several other things to note about this circuit. First the hydrogen FET drain/gate voltage is the output of the U3-1 opamp. While the controller will work with the drain tied to a fixed voltage and the gate tied to the output of U3-1, the response would then also be a function of the variability of the fixed voltage. 


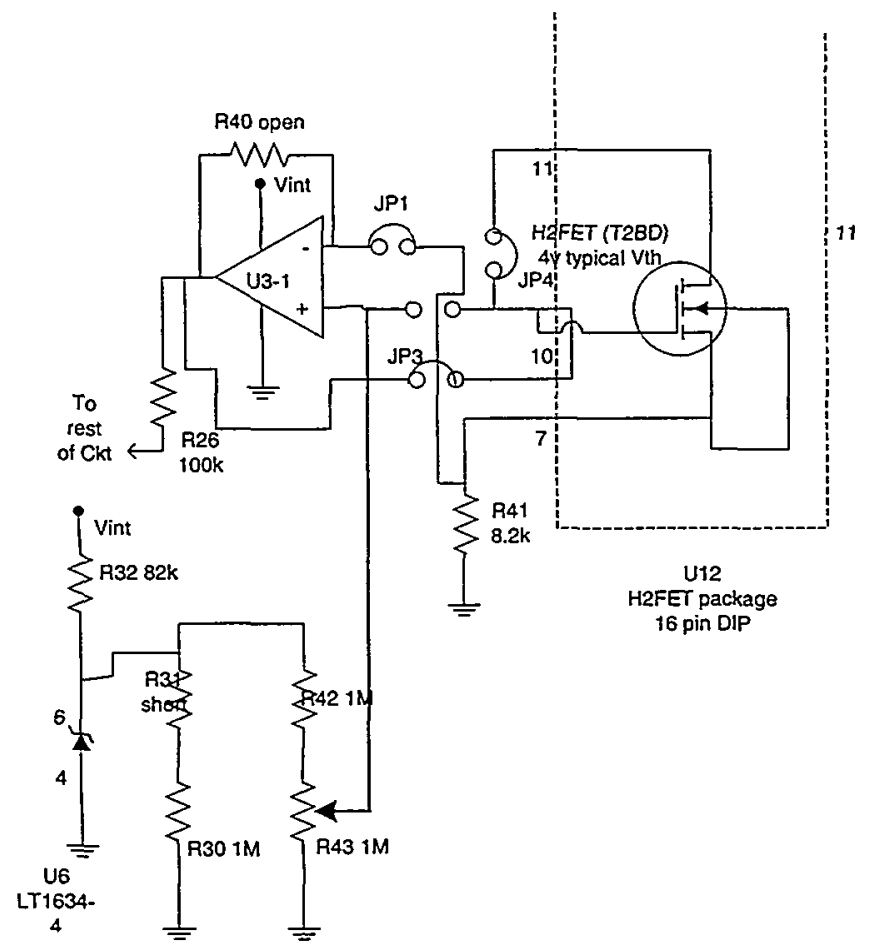

Figure B-1. Version 2 Hydrogen FET Biasing Circuit Schematic

In this application the fixed voltage is the doubler output which changes with time. This produces a significant change in the $\mathrm{V}_{\mathrm{th}}$ measurement and cannot be tolerated. Tying the drain/gate to the output of U3-1 makes the response only a function of the FET current (and of course the hydrogen concentration). Also note that the circuit board was designed to configure either the LM134 or the current controller above. The jumpers JP1-JP4 are used to select which current control method is used. JP1, JP3 and JP4 are shown installed for the method discussed above. The rest of the circuitry on the version 2 board is the same as the version 1 board except for the addition of R42 and R43 which are used to set the current hydrogen FET current as discussed above. 


\section{Appendix C Data Tabulations}


Table C-1. Calibration Data for FETs 2536 and 2541

FET 2536

\begin{tabular}{|ccc|ccc|ccc|ccc|}
\hline $\begin{array}{c}\text { 0\% Oxygen } \\
\mathbf{H}_{2} \text { conc., } \\
\text { ppm }\end{array}$ & $\begin{array}{c}\text { Signal, } \\
\text { volts }\end{array}$ & $\begin{array}{c}\text { Signal, } \\
\text { counts }\end{array}$ & $\begin{array}{c}\mathrm{H}_{2} \text { conc., } \\
\text { ppm }\end{array}$ & $\begin{array}{c}\text { Signal, } \\
\text { volts }\end{array}$ & $\begin{array}{c}\text { Signal, } \\
\text { counts }\end{array}$ & $\begin{array}{c}\mathbf{H}_{2} \text { conc., } \\
\text { ppm }\end{array}$ & $\begin{array}{c}\text { Signal, } \\
\text { volts }\end{array}$ & $\begin{array}{c}\text { Signal, } \\
\text { counts }\end{array}$ & $\begin{array}{c}\mathbf{H}_{2} \text { conc., } \\
\text { ppm }\end{array}$ & $\begin{array}{c}\text { Signal, } \\
\text { volts }\end{array}$ & $\begin{array}{c}\text { Signal, } \\
\text { counts }\end{array}$ \\
\hline 9.5 & 0.980572 & 148 & 9.5 & 0.678886 & 71 & 9.5 & 0.667837 & 68 & 8.0 & 0.643047 & 62 \\
50 & 1.09648 & 178 & 50 & 0.799342 & 102 & 50 & 0.768779 & 94 & 50 & 0.714157 & 80 \\
100 & 1.12667 & 185 & 100 & 0.886565 & 124 & 100 & 0.84905 & 115 & 100 & 0.783077 & 98 \\
500 & 1.16993 & 196 & 500 & 1.10012 & 179 & 500 & 1.03715 & 162 & 500 & 0.941603 & 138 \\
1000 & 1.18325 & 200 & 1000 & 1.16641 & 195 & 1000 & 1.13431 & 187 & 1000 & 0.99251 & 151 \\
2000 & 1.20074 & 204 & 2000 & 1.1988 & 204 & 2000 & 1.19794 & 203 & 2000 & 1.07585 & 172 \\
5000 & 1.22339 & 210 & 5000 & 1.22633 & 211 & 5000 & 1.22871 & 211 & 5000 & 1.22132 & 209 \\
8000 & 1.2361 & 213 & 8000 & 1.23934 & 214 & 8000 & 1.24189 & 215 & 8000 & 1.23962 & 214 \\
10000 & 1.24762 & 216 & 10000 & 1.25088 & 217 & 10000 & 1.25336 & 218 & 10000 & 1.25284 & 217 \\
8000 & 1.23959 & 214 & 8000 & 1.24167 & 215 & 8000 & 1.244 & 215 & 8000 & 1.24135 & 215 \\
5000 & 1.22985 & 212 & 5000 & 1.23113 & 212 & 5000 & 1.23263 & 212 & 5000 & 1.22512 & 210 \\
2000 & 1.2112 & 207 & 2000 & 1.20743 & 206 & 2000 & 1.20565 & 205 & 2000 & 1.05023 & 166 \\
1000 & 1.19625 & 203 & 1000 & 1.17853 & 199 & 1000 & 1.09321 & 177 & 1000 & 0.979963 & 148 \\
500 & 1.18593 & 200 & 500 & 1.06664 & 170 & 500 & 1.02197 & 159 & 500 & 0.941745 & 138 \\
100 & 1.1546 & 192 & 100 & 0.864088 & 118 & 100 & 0.845706 & 114 & 100 & 0.806436 & 104 \\
50 & 1.13799 & 188 & 50 & 0.812815 & 105 & 50 & 0.797569 & 101 & 50 & 0.760689 & 92 \\
9.5 & 1.09956 & 178 & 9.5 & 0.688658 & 74 & 9.5 & 0.681322 & 72 & 9.5 & 0.658809 & 66 \\
\hline
\end{tabular}

\section{FET 2541}

\begin{tabular}{|c|c|c|c|c|c|c|c|c|c|c|c|}
\hline \multicolumn{3}{|c|}{$0 \%$ Oxygen } & \multicolumn{3}{|c|}{$3 \%$ Oxygen } & \multicolumn{3}{|c|}{$5 \%$ Oxygen } & \multicolumn{3}{|c|}{$20 \%$ Oxygen } \\
\hline $\begin{array}{c}\mathrm{H}_{2} \text { conc, } \\
\text { ppm }\end{array}$ & $\begin{array}{l}\text { Signal, } \\
\text { volts }\end{array}$ & $\begin{array}{l}\text { Signal, } \\
\text { counts }\end{array}$ & $\begin{array}{c}\mathrm{H}_{2} \text { conc, } \\
\text { ppm }\end{array}$ & $\begin{array}{l}\text { Signal, } \\
\text { volts }\end{array}$ & $\begin{array}{l}\text { Signal, } \\
\text { counts }\end{array}$ & $\begin{array}{c}\mathrm{H}_{2} \text { conc. } \\
\text { ppm }\end{array}$ & $\begin{array}{c}\text { Signal, } \\
\text { volts }\end{array}$ & $\begin{array}{l}\text { Signal, } \\
\text { counts }\end{array}$ & $\begin{array}{c}\mathbf{H}_{2} \text { conc. } \\
\text { ppm }\end{array}$ & $\begin{array}{l}\text { Signal, } \\
\text { volts }\end{array}$ & $\begin{array}{l}\text { Signal, } \\
\text { counts }\end{array}$ \\
\hline 9.5 & 1.1835 & 200 & 9.5 & 0.920912 & 133 & 9.5 & 0.906401 & 129 & 8.0 & 0.88978 & 125 \\
\hline 50 & 1.24314 & 215 & 50 & 1.00614 & 155 & 50 & 0.9777 & 147 & 50 & 0.934729 & 136 \\
\hline 100 & 1.26387 & 220 & 100 & 1.07144 & 171 & 100 & 1.04117 & 163 & 100 & 0.98151 & 148 \\
\hline 500 & 1.29499 & 228 & 500 & 1.26063 & 219 & 500 & 1.22882 & 211 & 500 & 1.11551 & 182 \\
\hline 1000 & 1.30455 & 231 & 1000 & 1.29489 & 228 & 1000 & 1.29042 & 227 & 1000 & 1.17306 & 197 \\
\hline 2000 & 1.31719 & 234 & 2000 & 1.31597 & 234 & 2000 & 1.31744 & 234 & 2000 & 1.2811 & 225 \\
\hline 5000 & 1.33377 & 238 & 5000 & 1.33569 & 239 & 5000 & 1.33807 & 239 & 5000 & 1.33453 & 238 \\
\hline 8000 & 1.34343 & 241 & 8000 & 1.34557 & 241 & 8000 & 1.34767 & 242 & 8000 & 1.34675 & 241 \\
\hline 10000 & 1.35212 & 243 & 10000 & 1.3543 & 243 & 10000 & 1.35628 & 244 & 10000 & 1.35611 & 244 \\
\hline 8000 & 1.34641 & 241 & 8000 & 1.34758 & 242 & 8000 & 1.34925 & 242 & 8000 & 1.34808 & 242 \\
\hline 5000 & 1.33932 & 240 & 5000 & 1.33977 & 240 & 5000 & 1.34137 & 240 & 5000 & 1.33761 & 239 \\
\hline 2000 & 1.32527 & 236 & 2000 & 1.32268 & 235 & 2000 & 1.32295 & 235 & 2000 & 1.29198 & 227 \\
\hline 1000 & 1.31428 & 233 & 1000 & 1.30498 & 231 & 1000 & 1.3006 & 230 & 1000 & 1.17151 & 197 \\
\hline 500 & 1.30669 & 231 & 500 & 1.2816 & 225 & 500 & 1.23495 & 213 & 500 & 1.1273 & 185 \\
\hline 100 & 1.28287 & 225 & 100 & 1.0661 & 170 & 100 & 1.04827 & 165 & 100 & 1.00211 & 154 \\
\hline 50 & 1.27076 & 222 & 50 & 1.02194 & 159 & 50 & 1.00737 & 155 & 50 & 0.967717 & 145 \\
\hline 9.5 & 1.241 & 214 & 9.5 & 0.922766 & 133 & 9.5 & 0.916778 & 132 & 9.5 & 0.897991 & 127 \\
\hline
\end{tabular}




\section{DISTRIBUTION:}

DCH Technology

Attn: Denis Reid

27811 Avenue Hopkins

Suite 6

Valencia, CA 91355

Lawrence Livermore National Laboratory

Attn: Erica Von Holtz

Mail Stop L125

7000 East Avenue

Livermore, CA 94550-9234

1 MS 1073 Mike Daily, 1738

3 MS 1073 George Dulleck, 1738

5 MS 9014 Scott Faas, 2251

1 MS 1425 Robert Hughes, 1715

1 MS 9033 Robert Kinzel, 2221

1 MS 9015 Corey Knapp, 2220

1 MS $1033 \quad$ Scott Kuzmaul, 6211

1 MS 9014 Patricia Larson

1 MS 1425 Steve Martin, 1715

1 MS 0481 Mike Moulton, 2167

1 MS 9106 Bob Oetken, 8415

1 MS 9106 Debra Post, 8415

1 MS 9108 Carl Pretzel, 8414

1 MS 9106 Richard Roy, 8415

1 MS 0525 Kurt Wessendorf, 1732

1 MS 1054 Anton West, 7100

1 MS 9033 Beth Wichman, 2221

1 MS 9033 William G. Wilson, 2250

3 MS 9018 Central Technical Files, 8940-2

1 MS 0899 Technical Library, 4916

1 MS 9021 Technical Communications Department, 8528/

Technical Library, MS 0899, 4916

1 MS 9021 Technical Communications Department, 8528 For DOE/OSTI 